\title{
ESTUDIO DE LA CERÁMICA MEDIEVAL DE COVA EIRÓS (TRIACASTELA, LUGO)*
}

\author{
MARIO CÉSAR VILA \\ Horizontenorte (arqueoloxía, patrimonio, historia e enxeñaría cultural) \\ ORCID iD: http://orcid.org/0000-0001-8656-228X \\ Arturo de Lombera Hermida \\ Universidad de Santiago de Compostela \\ ORCID iD: http://orcid.org/0000-0001-9199-6242 \\ RAMÓN FÁBREGAS VALCARCE \\ Universidad de Santiago de Compostela \\ ORCID iD: http://orcid.org/0000-0002-7940-6884 \\ Xosé-Pedro Rodríguez-Állvarez \\ Universitat Rovira i Virgili-Institut Català de Paleoecologia Humana i Evolució Social \\ ORCID iD: http://orcid.org/0000-0002-1852-2283
}

\begin{abstract}
* Deseamos expresar nuestra gratitud a los siguientes investigadores y profesionales, que de una manera u otra han realizado aportaciones al presente trabajo: María Remedios Serna González, Enrique Alcorta Irastorza, Francisco Alonso Toucido, Roberto Bartolomé Abraira y María Catalina López Pérez. La parte gráfica ha sido elaborada por María Remedios Serna González (dibujo) y Mario César Vila (digitalización). Asimismo, agradecemos a la arqueóloga Manuela Mato, la disponibilidad de los materiales recogidos en la intervención realizada en Rúa do Pexigo 4. La campañas arqueológicas en Cova Eirós en los años 2015-2017 fueron financiadas por la Consellería de Cultura, educación y Ordenación Universitaria de la Xunta de Galicia.
\end{abstract}

Copyright: C 2018 CSIC. La edición electrónica de esta revista se distribuye bajo los términos de una licencia de uso y distribución Creative Commons Reconocimiento 4.0 Internacional (CC BY 4.0).

Cómo citar/Citation: Mario César Vila, Arturo de Lombera Hermida, Ramón Fábregas ValCarce y Xosé Pedro Rodríguez Álvarez, "Estudio de la cerámica medieval de Cova Eirós (Triacastela, Lugo)", Cuadernos de Estudios Gallegos, 65, núm. 131 (2018), págs. 73-105, https://doi. org/10.3989/ceg.2018.131.03 


\section{ESTUDIO DE LA CERÁMICA MEDIEVAL DE COVA EIRÓS (TRIACASTELA, LUGO)}

\section{RESUMEN}

Las intervenciones arqueológicas efectuadas a partir del año 2008 en el yacimiento de Cova Eirós (Triacastela, Lugo), pusieron a la luz evidencias materiales de diferentes contextos cronológicos. En este trabajo se aborda el análisis e interpretación de uno de los elementos de la cultura material más representativo de los depósitos de Cova Eirós, correspondiente a la cerámica de época histórica. Destaca la amplia presencia de tipos de época medieval, principalmente de la fase inicial y plena y de manera testimonial de Época Romana y Tardorromana. El grueso de estos materiales cerámicos pertenece a la producción de cerámica gris medieval del noroeste peninsular, siendo identificadas formas inéditas, cuanto menos desde el punto de vista historiográfico. Asimismo, se destaca la excepcional posición estratigráfica de buena parte de estos materiales, vinculados a contextos cerrados (fosas), sobre las que se llevan realizando dataciones radiocarbónicas, permitiendo asociar estas formas a dataciones de carácter absoluto. De este modo, las ocupaciones medievales en Cova Eirós pueden considerarse como reflejo de los cambios en la estructuración del territorio que se producen entre los siglos VIII-XI en el Noroeste peninsular y que son la raíz del poblamiento rural gallego. PALABRAS ClaVE: Cova Eirós, cerámica común romana, cerámica medieval, datación radiocarbónica, contexto cerrado.

\section{RESUMO}

\section{ESTUDO DA CERÁMICA MEDIEVAL DE COVA EIRÓS (TRIACASTELA, LUGO)}

As intervencións arqueolóxicas efectuadas a partir do ano 2008 no xacemento de Cova Eirós (Triacastela, Lugo), puxeron á luz evidencias materiais de diferentes contextos cronolóxicos. Neste traballo abórdase a análise e interpretación dun dos elementos da cultura material máis representativo dos depósitos de Cova Eirós, correspondente á cerámica de época histórica. Destaca a ampla presenza de tipos de época medieval, principalmente da fase inicial e plena e de xeito testemuñal de Época Romana e Tardorromana. $\mathrm{O}$ groso destes materiais cerámicos pertence á produción de cerámica gris medieval do Noroeste peninsular, sendo identificadas formas inéditas, canto menos dende o punto de vista historiográfico. Así mesmo, destácase a excepcional posición estratigráfica de boa parte destes materiais, vinculados a contextos pechados (foxas), sobre as que se levan realizando datacións radiocarbónicas, permitindo asociar estas formas a datacións de carácter absoluto. Deste xeito, as ocupacións medievais de Cova Eirós poden considerarse como o reflexo dos cambios na estruturación territorial que se producen entre os séculos VIII-XI no Noroeste peninsular e que son a raíz do poboamento rural galego.

PALABRAS ClAVE: Cova Eirós, cerámica común romana, cerámica medieval, datación radiocarbónica, contexto pechado.

\section{ANALYSIS OF THE MEDIEVAL POTTERY FROM COVA EIRÓS (TRIACASTELA, LUGO)}

ABSTRACT

The archaeological digs carried out in Cova Eirós (Triacastela, Lugo) since 2008 have brought to light material culture from multiple chronologies. This paper deals with the analysis and interpretation of the significant pottery finds from historical periods. Among these, Early and Middle Medieval sherds are particularly numerous, together with a few fragments belonging to the Roman and Late Antiquity periods. Most vessels can be ascribed to the NW Iberian medieval gray ware and we have been able to identify morphologies previously unknown in the extant bibliography. Moreover, the stratigraphic context of many sherds is rather informative, since they were recovered from pits that have been $\mathrm{C} 14$ dated, therefore allowing associating those sherds with absolute dates. Thus, the medieval occupations at Cova Eirós can be framed within the territorial changes that took place between the 8th-11th centuries in NW Iberia and are the root of the traditional rural settlement of Galicia.

KEY WORDS: Cova Eirós, Roman common pottery, Medieval pottery, C14 dating, closed context. 

de los materiales cerámicos de época histórica, recuperados en el curso de las campañas arqueológicas realizadas en Cova Eirós a partir del año 2008. Estas actuaciones han proporcionado un importante caudal de información en torno al uso en época medieval de la cavidad, incluyendo estructuras de diverso tipo, numerosos restos cerámicos y algunas fechas radiocarbónicas asociadas ${ }^{1}$. La colección analizada presenta caracteres que permiten llevar el momento de fabricación de los tipos identificados a momentos tempranos de la Edad Media, si bien se han podido identificar algunas piezas de cronología romana y tardorromana.

Desde el inicio de las presentes campañas de excavación en Cova Eirós se pudo detectar la existencia, tanto en el área de entrada de la cavidad como en las salas interiores, de una significativa actividad encuadrable cronoculturalmente en un marco altomedieval. Se dispone a este respecto de tres tipos de evidencia: cultura material (básicamente cerámica), estructuras de hábitat o de almacenaje y algunos análisis radiométricos. El yacimiento se corresponde con una cavidad abierta en los materiales calizos de la Formación de Cándama y se emplaza en la ladera N-NW del Monte Penedo, a $780 \mathrm{~m}$ de altitud y $25 \mathrm{~m}$ sobre el pequeño arroyo de Bezcas (fig. 1). La entrada de la caverna tiene una altura de $2 \mathrm{~m}$ en la actualidad y algo más de $3 \mathrm{~m}$ de ancho a lo largo de sus primeros $18 \mathrm{~m}$ de desarrollo, tras lo cual se estrecha notablemente durante otros $20 \mathrm{~m}$ hasta dar paso a la gran sala interior (Gran Sala o Sala do Mamut) y a una serie de galerías que se abren desde esta última hacia el interior del complejo kárstico.

En el área de la entrada se descubrieron dos fosas (UA-1 y UA-2), de $1 \mathrm{~m}$ de diámetro y $1,3 \mathrm{~m}$ de profundidad, excavadas en los rellenos pleistocenos y que contenían huesos, semillas de trigo y lino, carbones y numerosos restos cerámicos, cuya disposición sugiere que, antes de ser abandonadas, estas estructuras fueron

\footnotetext{
1 Ramón Fábregas ValCarce et al., "Ocupacións prehistóricas e históricas nas cavidades das Serras Orientais galegas. As covas de Eirós (Triacastela) e Valdavara (Becerreá)", Gallaecia, 31 (2012), págs. 19-46; Andrés TeIRA BRIÓN et al., "Forest resource management during Roman and Medieval cave occupations in the Northwest of the Iberian Peninsula: Cova do Xato and Cova Eirós (Lugo, Galicia, Spain)", Saguntum, núm. extra 13 (2012), págs. 159-166.
} 

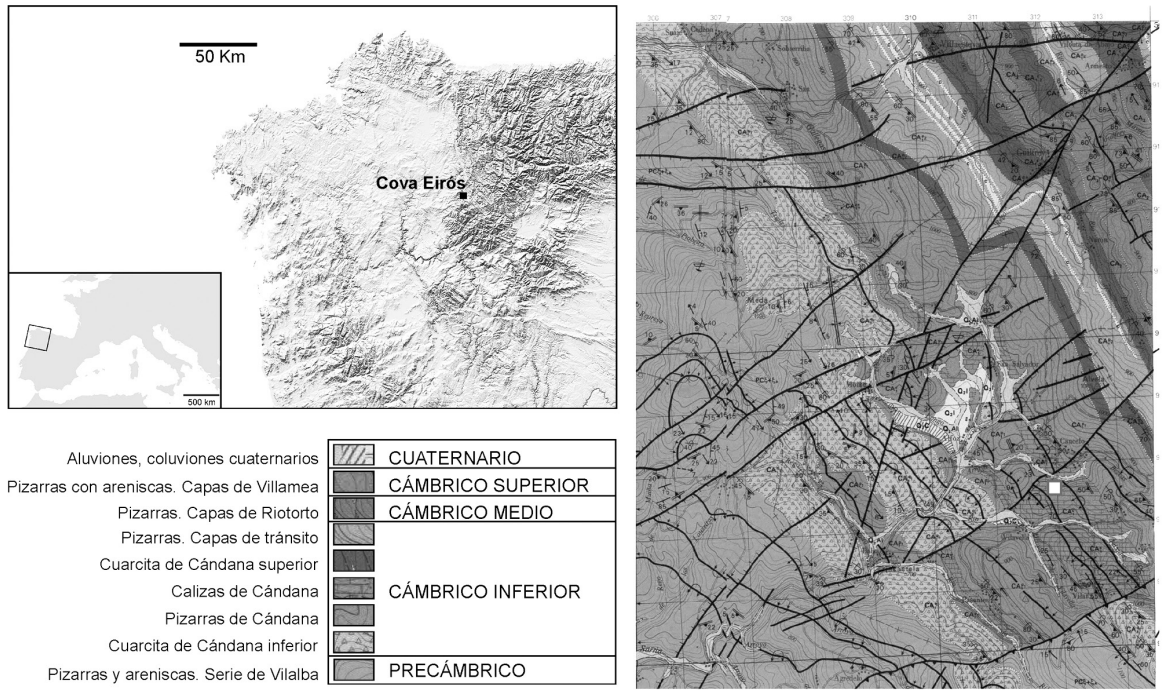

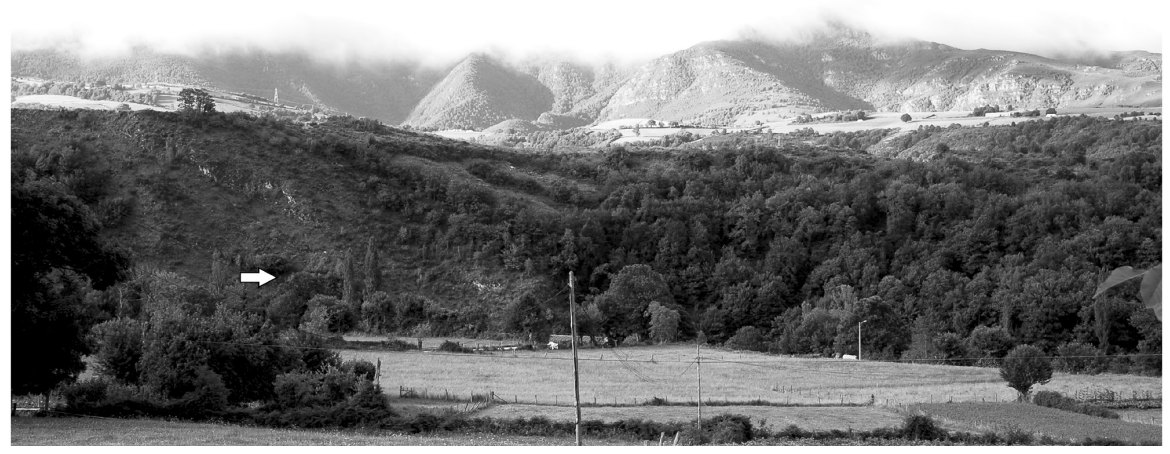

Fig. 1. Localización del yacimiento de Cova Eirós en el contexto geográfico y geológico noroccidental. Abajo, vista de la ladera donde se emplaza la entrada de la cavidad (flecha).

rellenadas en varias ocasiones como silos de almacenamiento ${ }^{2}$. Un hogar asociado a ambas estructuras proporcionó una fecha radiocarbónica (Beta-308578) que apunta a un período oscilando entre el 970 y el 1030 AD (Tabla 1). Tanto éste último como las fosas se distribuyen en un área acondicionada mediante la deposición perimetral de cantos de cuarcita de procedencia fluvial y bloques de caliza, entre los cuales se recuperaron restos de fauna doméstica (suidos, ovicápridos, bóvidos), algunos con nítidas marcas de corte (fig. 2). La totalidad del conjunto

\footnotetext{
2 A. TEIRA BRIÓn et al., "Forest resource management...,", págs. 159-166.
} 


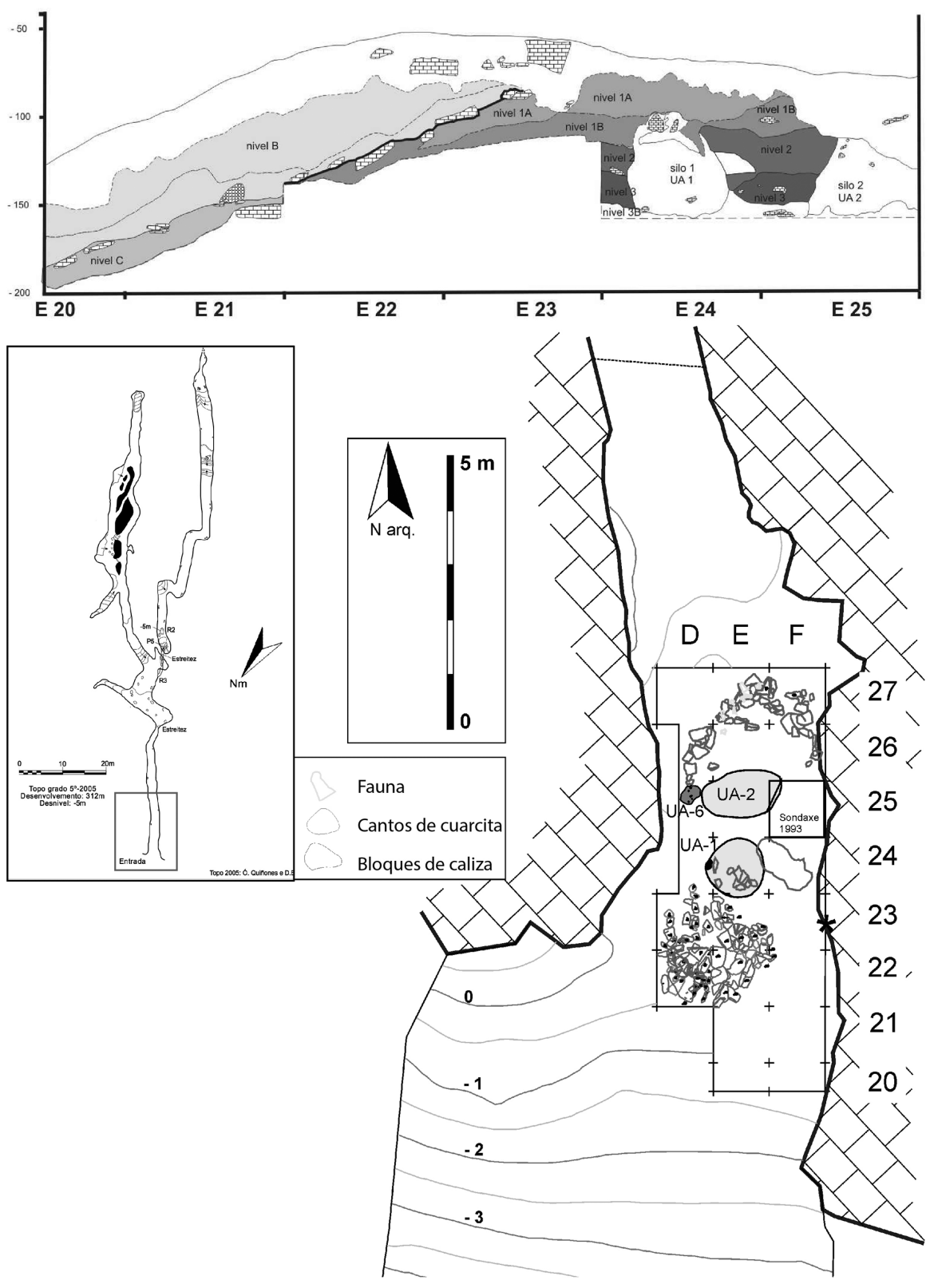

Fig. 2. Perfil estratigráfico W de Cova Eirós con la localización de los silos y del nivel superficial (en blanco). Planta de la cavidad y estructuras de época medieval en la entrada de Cova Eirós. Silos de almacenaje (UA 1 y UA2), hogar (UA 6) y empedrado perimetral. 
cerámico aquí analizado procede de las mencionadas estructuras de almacenaje y del nivel superficial de la cavidad. Hemos de señalar el carácter removido de esas unidades estratigráficas, ya sea por la propia amortización de las estructuras de almacenaje como por la alteración del nivel superficial. No se observan diferencias entre las facturas o tipos cerámicos identificados en cada una de las estructuras, lo que imposibilita establecer una diferenciación cronológica entre ellas. Por esta razón la cerámica de Eirós es analizada de forma conjunta.

Los análisis carpológicos y antracológicos llevados a cabo en este sector han proporcionado una visión bastante completa de las características y aprovechamiento del medio vegetal, apuntando a una significativa deforestación del entorno, motivada por la roturación agrícola, cuyos resultados se plasman en el almacenamiento de cereal dentro de las fosas excavadas en la zona de la entrada ${ }^{3}$. No obstante, el uso con fines de almacenaje en época altomedieval no debe haber sido la única razón para la presencia humana en la cavidad, pues también se han documentado actividades de carácter más doméstico y evidencias de interpretación más ambigua, como el gran fuego encendido en la Sala do Mamut -cuyo hollín, extendido por la pared inmediata, proporcionó una datación estadísticamente idéntica a Beta-333971-, así como otros indicios de deambulación por las galerías interiores (tizonazos y carbones entre las fisuras de los paneles). Las fechas radiométricas disponibles encuadran estos episodios del interior de la cavidad en el mismo marco cronológico definido para el sector de la entrada. La combinación de todas ellas, sitúa unas y otras evidencias medievales en el periodo 982-1024 cal AD (95,4\%) (Tabla 1). Si bien las tres dataciones coinciden en un estrecho rango temporal, no debemos considerarlas como evidencias de un único momento de ocupación o utilización de la cavidad. Las propias características tipológicas del conjunto cerámico nos indican que la ocupación histórica de Cova Eirós se extiende bastante más en el tiempo.

Tabla 1. Fechas radiocarbónicas procedentes de contextos medievales de Cova Eirós

\begin{tabular}{|l|l|l|l|l|}
\hline PROCEDENCIA & REF. LABORATORIO & MUESTRA & EDAD RADIOCARBÓNICA BP & EDAD CALIBRADA \\
\hline $\begin{array}{l}\text { Hogar entrada } \\
\text { (UA6) }\end{array}$ & Beta - 308578 & $\begin{array}{l}\text { Carbón } \\
\text { (Fabaceae) }\end{array}$ & $1040 \pm 30$ & $901-1033 \mathrm{AD}$ \\
\hline $\begin{array}{l}\text { Hoguera } \\
\text { Gran Sala }\end{array}$ & Beta - 333971 & Carbón & $1020 \pm 30$ & $969-1046 \mathrm{AD}$ \\
\hline $\begin{array}{l}\text { Fisura inmediata } \\
\text { al panel XI }\end{array}$ & Beta - 345400 & $\begin{array}{l}\text { Carbón } \\
\text { (Quercus sp. })\end{array}$ & $1050 \pm 30$ & $900-1027 \mathrm{AD}$ \\
\hline $\begin{array}{l}\text { Fecha } \\
\text { Combinada }\end{array}$ & & $1037 \pm 18$ & $982-1024 \mathrm{AD}$ \\
\hline
\end{tabular}

\footnotetext{
A. TEIRA BRIón et al., "Forest resource management...”, págs. 159-166.
} 


\section{LA COLECCIÓN CERÁMICA: ASPECTOS GENERALES}

El grueso del conjunto se compone de piezas muy fragmentadas, si bien su reconstrucción podría ser segura en una parte de los ejemplares. Los bordes proporcionan información inequívoca sobre las características formales de las piezas, al igual que los fondos recogidos. De todos modos, son contados los casos en los que se ha podido rehacer una parte sustancial de la vasija a partir de los bordes conservados. La parte correspondiente al cuerpo apenas permite destacar elementos de atribución formal, si bien bastantes ejemplares apuntan a formas globulares, así como a técnicas y motivos decorativos comunes a las tradiciones cerámicas del norte y noroeste peninsular.

A partir del análisis visual y por lo tanto con las debidas cautelas en cuanto a datos concluyentes, se han podido diferenciar varios tipos de factura, a los que se asocian también pastas diferentes. El bloque principal de las cerámicas lo componen piezas con pastas de tonalidades grises y castaño, que dominan ampliamente en el conjunto. Se corresponden con pastas ligeras y en general porosas, en las que son visibles los desgrasantes de cuarzo y mica de forma generalizada, a veces en cantidades importantes y calibrado deficiente, afectando a la calidad de las pastas y resultando perfectamente visibles en la superficie. Por otra parte existen pequeños conjuntos que denotan procedimientos de factura y materiales diferentes, además del tipo de cocción, que podrían estar vinculados a una fabricación exógena o foránea, no correspondiendo a la producción común del NW.

Una pequeña muestra de las vasijas presenta pastas rojas que denotan una cocción oxidante, bien decantadas y con desgrasantes finos ${ }^{4}$. Los fragmentos presentan cierta tendencia a la exfoliación en las roturas y en el desgaste superficial. En algunos de ellos se observa un baño superficial o aguada, de tonalidad más rosada o tostada, que contrasta con el rojo-naranja fuerte de las pastas. Si bien no resulta fácil el reconocimiento formal, en general por el tamaño reducido de los fragmentos, la simple diferencia de acabado podría apuntar a la presencia de algunos tipos, incluyendo una gran tinaja que muestra estrías de torno muy destacadas al interior en la zona cercana al fondo.

\section{CerámicA COMÚn ROMANA y TARdORROMAna (fig. 3: 5)}

Cerámicas grises tardías finas (fig. 3: 1-4)

Entre los materiales estudiados, se localizaron cuatro ejemplares cuyas características formales, el tipo de pastas de tonalidad gris, la calidad de acabados y

\footnotetext{
4 Para la descripción de tonalidades, se ha utilizado la tabla de colores de suelos de André CAILLEux, Notice sur le code des couleurs des sols, Paris, Boubée, 1963.
} 
MARIO CÉSAR VILA, ARTURO DE LOMBERA HERMIDA,

técnica, permiten adscribirlas a las cerámicas grises finas tardías englobadas dentro de la cerámica común romana de imitación. Dentro de este conjunto se engloban formas abiertas que conforman un servicio de mesa de inspiración clásica y que han sido objeto de estudio durante las últimas décadas, con cronologías propuestas que abarcan desde la Época Romana Tardía hasta la Alta Edad Media5.

Los perfiles que presentan estas piezas parecen imitar la forma Hayes 61/ Lamboglia 54, 53bis, correspondientes a la producción de TSAD.

Dos de estos ejemplares (fig. 3: 1-2), conservan el borde y la parte superior del cuerpo, pudiendo calcularse su diámetro $(26,4$ y $30,2 \mathrm{~cm})$. La pieza $\mathrm{N}^{\mathrm{o}} 1$, de mayor diámetro, imitaría al tipo Hayes 61A de TSAD, para el que se establece una cronología del 325 al 400 d.C.

Otro de los ejemplares (fig. 3: 2) presenta borde vuelto al interior, sección redondeada y paredes abiertas. Los dos fragmentos restantes (fig. 3: 3-4), conservan el borde y parte del cuerpo y podrían estar igualmente imitando a la forma Hayes 61/Lamboglia 54, 53bis de TSAD.

Esa forma se corresponde con una escudilla de borde vertical inclinado al interior de sección triangular, pared curva y fondo plano. La fabricación del tipo de TSAD que inspiraría esta imitación, abarca del 325 al 450 d.C. si bien al tratarse de una imitación, esta fecha podría prolongarse.

Plato engobado: EP1 (fig. 3: 5)

Entre los materiales localizados, se pudo identificar un plato engobado de borde biselado, conocido como Tipo EP1 (fig. 3: 5), de la clasificación de Alcorta ${ }^{6}$. Si bien el ejemplar muestra diferencias (pasta menos depurada, con abundantes vacuolas y engobe cubriente sobre ambas superficies) con respecto a los tipos más característicos de la producción lucense, los rasgos tipológicos y técnicos, permiten integrar el individuo de Cova Eirós dentro de esta forma.

Esta forma se caracteriza por presentar borde no diferenciado, biselado o redondeado, pared oblicua y base plana. La pasta es ocre y posee granos de cuarzo y micas como materiales no plásticos, si bien la calidad es más deficiente, con abundantes vacuolas, respecto a los ejemplares típicos de la producción lucense.

\footnotetext{
E. Alcorta Irastorza, Lvcvs Avgvsti, Vol. II: Cerámica común romana ..., págs. 382-392; A. FernándeZ Fernández y R. BARtolomé Abraira, “Cerámicas tardoantiguas en el Noroeste de la Península (Galicia y norte de Portugal: entre la importación y el artesanato local/regional (ss. V-VII)", en La cerámica de la Alta Edad Media en el cuadrante Noroeste de la Península Ibérica (siglos V-X), Sistemas de producción, mecanismo de distribución y patrones de consumo, Documentos de Arqueología Medieval, 9, Bilbao, Universidad del País Vasco, 2016, págs. 69-111; Roberto BARTolomé ABraira, “Cerámica gris fina tardía. Los fondos resaltados de copas y cuencos carenados de Lucus Augusti”, Férvedes, 8, Vilalba (Lugo), 2015, págs. 371-380.

6 E. Alcorta Irastorza, Lvcvs Avgvsti, Vol. II: Cerámica común romana ..., págs. 344-346.
} 
Cerámica común romana: cerámicas grises finas tardías

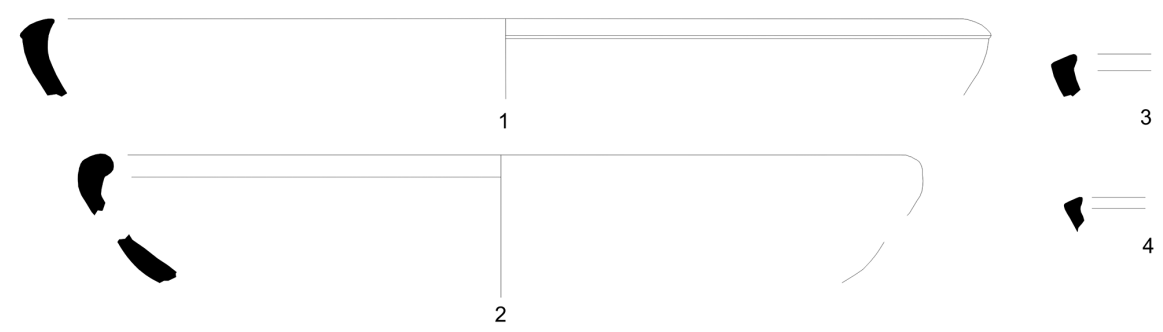

Cerámica común romana: Plato engobado EP1

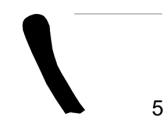

Cerámica medieval: Olla/vaso de borde simple
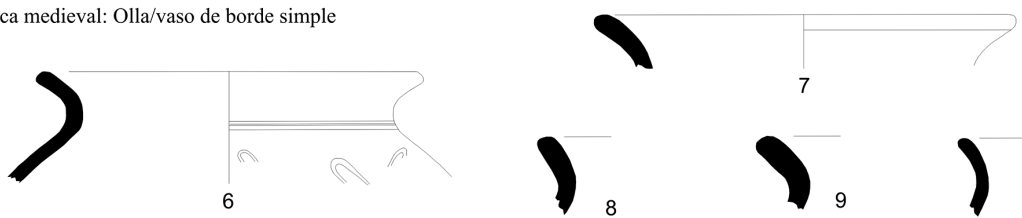

8

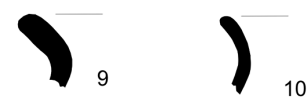

Cerámica medieval: Olla de borde horizontal cóncavo
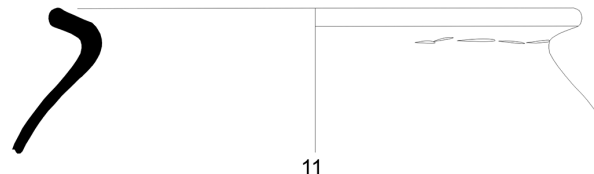

11

Cerámica medieval: Olla de borde horizontal apuntado
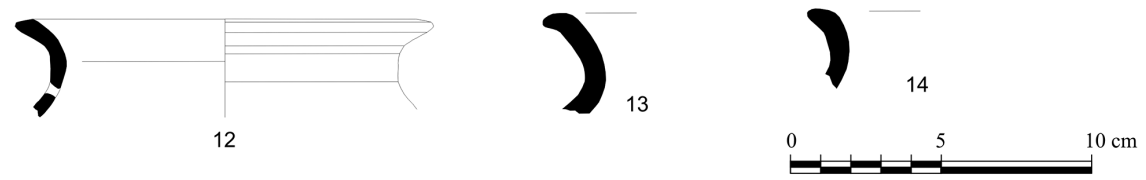

Fig. 3. Cerámica común romana: cerámicas grises finas y plato engobado de borde biselado EP1. Cerámica común medieval: olla/vaso de borde simple, olla de borde horizontal cóncavo y olla de borde horizontal apuntado. 
Al exterior presenta el engobe que caracteriza los platos del grupo formal, de color rojizo, adherente y homogéneo.

Respecto a la cronología, el éxito propiciado por su carácter práctico y sencillo, así como su fácil apilado para el transporte, hizo que el tipo se fabricase a lo largo del período productivo indicado.

\section{CerámicA COMÚN MEdieval del Noroeste Peninsular}

Esta producción compone la mayor parte del conjunto y presenta fabricación a torno con pastas generalmente grises, fruto de una cocción reductora. La producción aparece diferenciada por una serie de elementos técnicos, tipológicos y físicos definidos para la Edad Media Plena y fundamentalmente para la Baja Edad Media gallega ${ }^{7}$.

Tras la realización de los análisis macroscópicos de pastas - de manera preliminar por lo tanto- y a partir de la comparación de estas con conjuntos vinculados a contextos medievales conocidos, semeja que el grueso del material estudiado se podría integrar en dicha producción. Los elementos no plásticos básicos los componen micas y cuarzos, siendo transformados en atmósferas reductoras.

\section{Olla/vaso ${ }^{8}$ de borde simple (fig. 3: 6-10)}

Este tipo se define como una olla de pequeñas dimensiones o vaso, de borde corto abierto con labio redondeado, cuerpo ovoide o esférico y base plana ${ }^{9}$. Es

\footnotetext{
7 Andrés Bonilla Rodríguez y Mario CÉSAR Vila, "Excavaciones arqueológicas en área en el solar de la antigua capilla y lazareto medieval de S. Lázaro (Santiago de Compostela, A Coruña)", Gallaecia, 24 (2005), págs. 219-242; Mario CÉsar Vila y Andrés Bonilla RodríGuEz, "Estudio de los materiales cerámicos del “Castelo da Lúa' (Rianxo, A Coruña)”, Gallaecia, 22 (2003), págs. 297-367; Mario CÉSAR Vila y Andrés Bonilla Rodríguez, "Síntesis de los materiales cerámicos procedentes del yacimiento de As Encrobas (Cerceda A Coruña)", en La cerámica en Galicia: de los castros a Sargadelos. Actas del XIV Congreso Anual, [Alicante], Asociación de Ceramología, 2011, págs. 141-152; Mario César Vila y María Catalina López PÉrez, "Aportaciones al conocimiento del comercio de sigillata en la fachada Atlántica del Noroeste Peninsular", Les productions céramiques en Hispanie Tarraconaise (IIe s. av. J.-C. -VIe s. apr. J.-C.) Actualité des recherches céramiques, Actes du Congrès de L'Escala-Empúries, Marseille, 2008, págs. 241-254; Francisco FARIÑa Busto, "Contribución ao estudo da cerámica medieval en Galicia", Cuadernos de Estudios Gallegos, 29, fasc. 87-89 (1974-75), págs. 51-64; José SuÁrez Otero et al., "La cerámica medieval en Galicia”, en José Avelino Gutiérrez González y Ramón Bohigas Roldán (coord. ed.), La cerámica medieval en el Norte y Noroeste de la Península Ibérica. Aproximación a su estudio, León, Universidad de León, 1989, págs. 285-301.

8 En este caso se propone la definición de olla y vaso ya que es probable que estos ejemplares, de tamaño reducido, pudieran ser utilizados de manera ambivalente, tanto como contenedores para la preparación, almacenamiento y transporte de substancias sólidas y líquidas, como para el consumo directo de las mismas. 9 M. César Vila y A. Bonilla Rodríguez, "Estudio de los materiales cerámicos...”, págs. 307-308; Mario CÉSAR VILA et.al., "Aportaciones al conocimiento de la cerámica producida en la última fase de la Edad media en Galicia, en Metodología de Análisis Aplicada a los Estudios de Cerámica Tardoantigua y Medieval de la Península Ibérica, Jornada internacional sobre metodología de análisis aplicada a los estudios de cerámica tardoantigua y medieval de la Península Ibérica, León, Universidad de León, 2010, págs. 150-151.
} 
un tipo generalizado en todas las fases de la edad media del Noroeste peninsular debido a su funcionalidad, hecho que condicionará su escaso desarrollo formal con el paso de las centurias. Sus prototipos podrían estar relacionados con las ollas globulares de borde exvasado oblicuo, sin decoración (O1) y los vasos ovoides de borde flexionado, sin decoración (V3) fabricados en la denominada segunda fase de la cerámica común romana del Noroeste peninsular ${ }^{10}$.

Esta forma ha sido detectada para el área galaica en la plazuela de San Paio de Antealtares y Rúa do Pexigo en la ciudad de Santiago de Compostela (A Coruña), en el castillo de A Rocha Forte (Santiago de Compostela, A Coruña), en fortaleza de Torre de Rianxo/Castelo da Lúa (Rianxo, A Coruña), en el castillo de Vimianzo (A Coruña) en niveles anteriores a la revuelta irmandiña, en el antiguo Pazo Provincial de A Coruña, en el monasterio de San Xoán de Caaveiro (A Coruña), en la ciudad de Lugo, en el yacimiento de Ouvigo (Blancos, Ourense) y en la Torre de Meira (Pontevedra) ${ }^{11}$.

La práctica totalidad de las estratigrafías en las que se documenta esta forma pertenecen a niveles de la Edad Media Plena y Baja. Su ausencia en niveles anteriores podría deberse a la escasez de contextos altomedievales en el territorio gallego, como corroborarían los hallazgos de Cova Eirós. Las piezas presentan diámetros en torno a los $12-13 \mathrm{~cm}$. Algún ejemplar muestra una serie de digitaciones onduladas oblicuas en la parte superior del cuerpo, características de este tipo.

Olla de borde horizontal cóncavo (fig. 3: 11)

Esta forma se caracteriza por presentar borde horizontal o levemente oblicuo con concavidad interior, destinada al asiento de tapaderas, rematado en labio redondeado ${ }^{12}$. El cuerpo es globular con perfil sinuoso, cuello estrangulado y base plana. Este tipo presenta cronología amplia, localizándose en Santiago de Compostela en contextos antiguos de la Edad Media Plena y perdurando hasta finales de la misma.

Se ha detectado la presencia de este tipo en San Paio de Antealtares, Acibechería en niveles de los siglos XII a XIV, en San Lázaro y A Rocha Forte, dentro de la ciudad de Santiago de Compostela. Asimismo se registra en la fortaleza de Torre de Rianxo/Castelo da Lúa (Rianxo) y de Vimianzo en contextos anteriores a la revuelta irmandiña, ciudad de A Coruña en el solar del antiguo Pazo Provincial, en el monasterio de San Xoán de Caaveiro (A Coruña), en la ciudad de Lugo, en

\footnotetext{
${ }_{10}$ E. Alcorta Irastorza, Lvcvs Avgviti, Vol. II: Cerámica común romana ..., págs. 193-196 y págs. 271273.

11 M. César Vila y A. Bonilla Rodríguez, "Estudio de los materiales cerámicos...”, págs. 307-308; M. CÉSAR VILA et.al., “Aportaciones al conocimiento de la cerámica producida...”, pág. 151.

12 A. Bonilla Rodríguez y M. César Vila, “Excavaciones arqueológicas en área en el solar...”, pág. 225;

M. CÉsar Vila y A. Bonilla Rodríguez, "Estudio de los materiales cerámicos...”, pág. 303.
} 
el yacimiento de Ouvigo (Blancos, Ourense), en Torre de Meira (Moaña, Pontevedra) y Valga (Pontevedra) ${ }^{13}$.

Un ejemplar recogido en Cova Eirós presenta un diámetro de borde de 17 $\mathrm{cm}$, con perforación post-cocción en el cuello, probablemente relacionada con la medición de líquidos.

Olla de borde horizontal apuntado (fig. 3: 12-14)

Esta forma se asemeja al tipo olla de borde horizontal cóncavo, si bien presenta diferencias en el borde -así como en sus dimensiones-. La forma se define por mostrar un borde totalmente horizontal, rematado en punta o sección triangular, cuerpo globular de perfil sinuoso, cuello estrangulado y probablemente base plana.

Uno de los ejemplares recogidos presenta un diámetro de borde de $14 \mathrm{~cm}$ y perforación realizada tras la cocción en el cuello.

Olla de borde rectangular (fig. 4: 15-18)

Esta forma de dimensiones reducidas presenta semejanzas con la olla y vaso de borde simple. Este es abierto y sencillo, de sección rectangular o levemente biselado, el cuello muestra línea de ruptura en ángulo recto, el cuerpo es globular y la base probablemente plana.

Olla de borde de pestaña (fig. 4: 19)

Este tipo ha sido considerado uno de los mejores fósiles directores para las centurias finales de la Edad Media, llegando a prolongarse su fabricación hasta bien entrada la Época Moderna. Más problemática resulta su fecha de inicio de fabricación. Formalmente se define por presentar un reborde vertical o inclinado externo al labio, siendo una de las formas mejor trabajadas a nivel técnico. Naveiro propuso una cronología que abarcaría desde finales del siglo XIII-siglo XIV hasta el XVI ${ }^{14}$.

A nivel formal presenta un cuello sinuoso, cuerpo globular y base plana ${ }^{15}$, empleándose arcillas depuradas para su elaboración.

Aparece representada en Santiago de Compostela en la gran cabecera gótica de la Catedral, en San Paio de Antealtares, Rúa Hortas, San Lázaro y en las fortalezas de A Rocha Forte, Torre de Rianxo/Castelo da Lúa (Rianxo, A Coruña), Moeche (Moeche, A Coruña), en la ciudad de A Coruña, siendo recogida en las intervenciones realizadas en el antiguo Pazo Provincial, Iglesia de Santiago, Rúa

\footnotetext{
${ }_{13}$ M. CÉSAR VILA et.al., “Aportaciones al conocimiento de la cerámica producida...”, pág. 149.

14 Juan Naveiro López, Los materiales arqueológicos de la Plaza de María Pita (A Coruña), Memoria inédita, 1986, pág. 33; lám. 29.

15 A. Bonilla Rodríguez y M. César Vila, “Excavaciones arqueológicas en área en el solar...”, pág. 226;

M. César Vila y A. Bonilla Rodríguez, "Estudio de los materiales cerámicos...”, pág. 305.
} 
Olla de borde rectangular
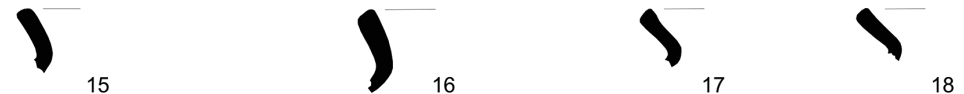

15

16

17

18

Olla de borde de pestaña

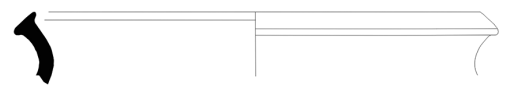

19

Olla de borde engrosado

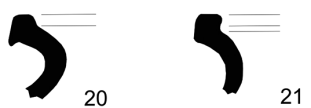

21

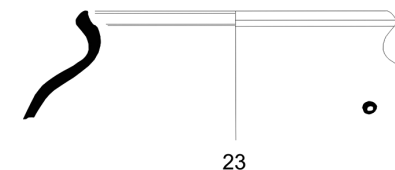

$\int$

22

,

5
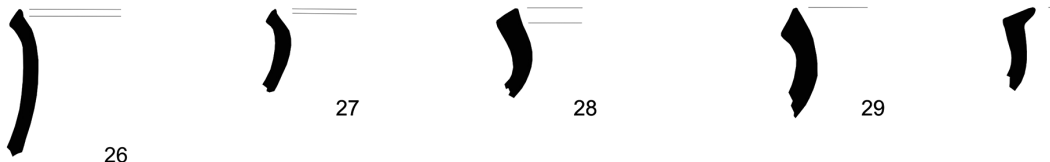

29

30

26
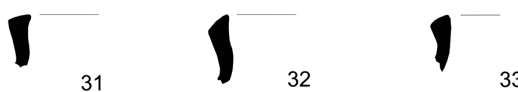

33
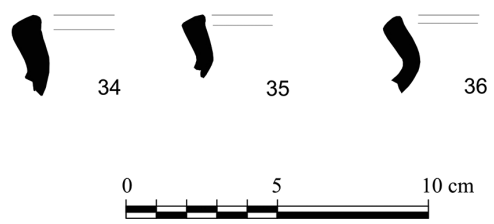

Fig. 4. Cerámica común medieval: olla de borde rectangular, olla de borde de pestaña, olla de borde engrosado y olla de borde biselado. 
da Franxa, Praza de Azcárraga y en María Pita. Se ha documentado en la ciudad de Lugo, en Praza de Campo Castelo y Rúa Nova, en el yacimiento de Ouvigo (Blancos, Ourense), así como en Valga (Pontevedra) ${ }^{16}$.

Únicamente ha sido identificado un ejemplar, formalmente diferenciado de las piezas conocidas en contextos de la edad media plena y baja, al presentar la pestaña totalmente perpendicular al engarce con el cuerpo y con similar dimensión a ambos lados del mismo - generalmente suele ser oblicuo y de mayor tamaño el reborde inferior-.

Olla de borde engrosado (fig. 4: 20-21)

Se trata de un tipo poco conocido que presenta borde engrosado o reforzado, de sección rectangular y cuello más o menos estrangulado. Se han recogido dos ejemplares, de los que no ha sido posible determinar el diámetro.

\section{Olla de borde biselado (fig. 4: 22-36)}

Esta forma aparece formalmente relacionada con la olla de borde horizontal cóncavo. Se diferencia por presentar un borde biselado o de sección triangular, seguido de una concavidad horizontal o levemente oblicua, ligada al encaje de tapaderas. Los ejemplares localizados en Cova Eirós, poseen un cuello alto y tendente a la verticalidad, prolongándose inferiormente para conformar un cuerpo troncocónico o alargado.

Han sido contabilizados catorce ejemplares, cuyos diámetros de borde se encuentran entre los 18 y los $10 \mathrm{~cm}$. Uno de ellos presenta decoración formada por una línea horizontal incisa realizada a mano alzada, formando un zig-zag, tanto en la parte interior como exterior del borde. Otro ejemplar tiene una perforación en la parte alta del cuerpo, realizada tras la cocción.

Olla de borde vuelto (fig. 5: 37-38)

La forma se corresponde con una olla de borde abierto engrosado de sección triangular, con la parte superior del borde plano o ligeramente cóncava, cuya apariencia recuerda al borde de pestaña, si bien no tan desarrollado. El cuello se muestra estrangulado y el cuerpo globular o semiesférico. Los dos ejemplares recogidos presentan diámetros entre 14 y $20 \mathrm{~cm}$ en el borde.

Olla de borde corto (fig. 5: 39-45)

Esta forma presenta borde corto simple o redondeado, cuello alto, escasamente estrangulado, que se prolongaría inferiormente formando un cuerpo troncocónico $\mathrm{u}$ ovoide, tendente a la verticalidad. A nivel decorativo, los ejemplares suelen

\footnotetext{
${ }_{16}$ M. CÉSAR VILA et.al., “Aportaciones al conocimiento de la cerámica producida...”, pág. 150.
} 
Olla de borde vuelto
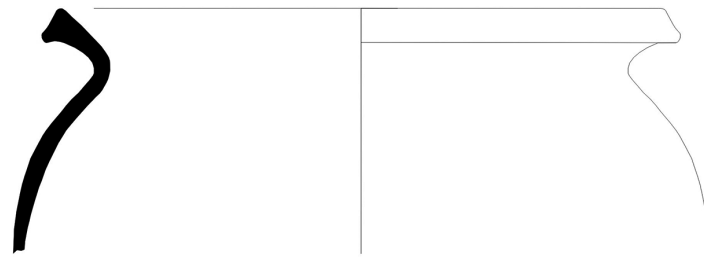

37

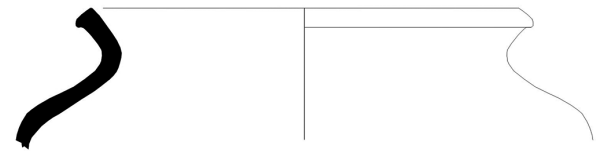

38

Olla de borde corto
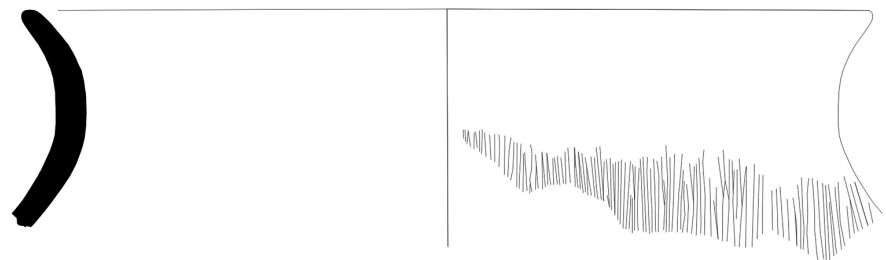

39
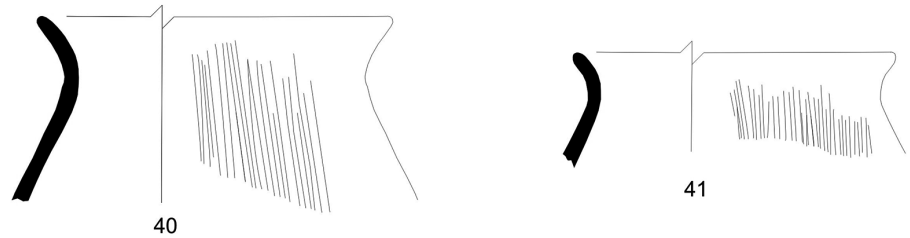

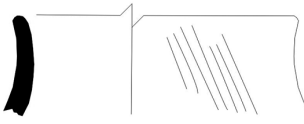

42

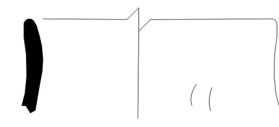

43
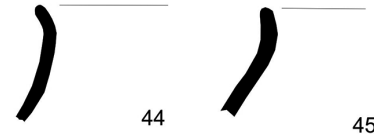

0

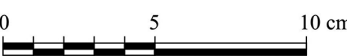

Fig. 5. Cerámica común medieval: Olla de borde vuelto y olla de borde corto. 
mostrar incisiones verticales u oblicuas en la parte superior del cuerpo y cuello, realizadas mediante peinado.

Olla de borde corto engrosado (fig. 6: 46-50)

Este tipo se caracteriza por presentar un borde corto engrosado abierto, de sección redondeada o ligeramente apuntada. El cuello puede ser más o menos estrangulado y el cuerpo aparentemente globular. Formalmente se asemeja bastante a la olla de borde corto, siendo característica la decoración peinada verticalmente sobre el cuello y la parte superior del cuerpo.

Vasija de borde plano (fig. 6: 51-61)

Debido a la fragmentación de las piezas, únicamente se ha podido describir la parte superior de las mismas y el borde. Con esta información se puede identificar como una forma con borde plano de sección triangular tendente a la verticalidad o ligeramente abierta. En algunos ejemplares se documenta un baquetón externo horizontal que actuaría a modo de refuerzo, lo que podría indicar cierta amplitud en los diámetros.

Vasija de borde bifido (fig. 6: 62-64)

Al igual que la forma anterior, apenas se han podido determinar características formales. El borde recuerda a la pieza de borde de pestaña localizada, si bien los extremos bífidos no presentan un desarrollo destacado respecto a esta.

Jarra de borde biselado (fig. 6: 65-66)

Se trata de una jarra que formalmente se asemeja a la olla de borde biselado, anteriormente descrita. Un ejemplar presenta retraimiento digital del borde con la pasta húmeda, formando el pico vertedor, semejante a la jarra trilobulada.

Jarra trilobulada (fig. 6: 67-69)

La jarra trilobulada constituye uno de los fósiles directores de la Edad Media plena europea y de ella existen numerosas referencias en el N y NW peninsular ${ }^{17}$. En Galicia, su aparición fue fechada entre los siglos XI-XIII ${ }^{18}$.

Se caracteriza físicamente por presentar borde con boca trilobulada de pico abierto, cuyo origen se podría relacionar con la cerámica común romana, concretamente en las jarras monoansadas de pico trilobulado abierto ${ }^{19}$.

\footnotetext{
17 José Avelino Gutiérrez GonzÁlez y Ramón Bohigas Roldán (coord. ed.), La cerámica medieval en el Norte y Noroeste de la Península Ibérica. Aproximación a su estudio, León, Universidad de León, 1989.

18 J. SuÁrez Otero et al., "La cerámica medieval en Galicia”, págs. 289.

19 E. Alcorta Irastorza, Lvcvs Avgvsti, Vol. II: Cerámica común romana ...., págs. 282-285.
} 


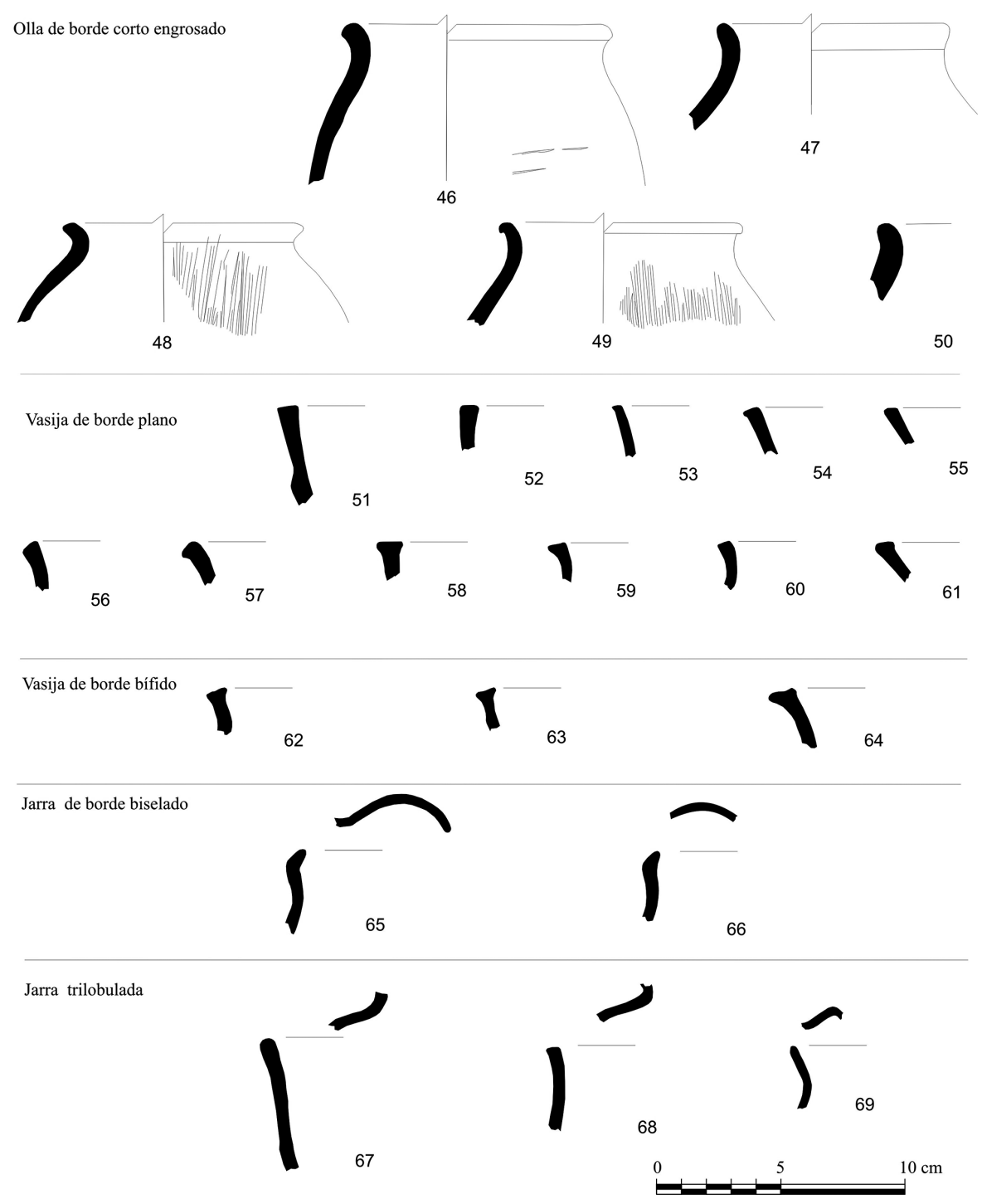

Fig. 6. Cerámica común medieval. Olla de borde engrosado, vasija de borde plano, vasija de borde bífido, jarra de borde biselado y jarra trilobulada. 
MARIO CÉSAR VILA, ARTURO DE LOMBERA HERMIDA, RAMÓN FÁBREGAS VALCARCE, XOSÉ-PEDRO RODRÍGUEZ-ÁLVAREZ

En Galicia ha sido localizada en San Lázaro y A Rocha Forte en Santiago de Compostela (A Coruña), Valga (Pontevedra) y en el Pazo do Bispo de Ourense, si bien su distribución sería bastante más amplia que la aquí esbozada.

Jarras indeterminadas (fig. 7: 70-79)

Varias de las jarras documentadas se han identificado a partir de la presencia de asas de cinta, típicas de la producción medieval plena, de la que se conocen ejemplos en toda la franja norte y noroccidental peninsular ${ }^{20}$. Un elemento característico lo compone la decoración en el exterior del asa formada por series de incisiones cortas verticales o punzonados ${ }^{21}$. El tipo trilobulado presenta una cronología que iría del siglo XI al XIII en el Noroeste peninsular ${ }^{22}$. Se diferencian asas con sección en cinta, típicas de la Edad Media Plena, con las características incisiones externas, de sección oval o rectangular.

En Gatillo, Trampal y Melque, se han registrado vasijas con asas de semejante tipología a la de varios ejemplares recogidos en Cova Eirós, para las que se ofrece una datación de entre el siglo VIII y IX ${ }^{23}$.

\section{Lebrillo o barreño (fig. 7: 80)}

Se trata de una forma troncocónica abierta que suele poseer asas de anillo o asideros en forma de reborde con digitaciones ${ }^{24}$ al que puede corresponder un ejemplar localizado en el yacimiento. Cabe la posibilidad de que el fragmento perteneciese a un recipiente especializado, denominado pote meleiro, de larga tradición y que se remonta en sus ejemplares más antiguos a la Edad del Hierro Antiguo Ibérico. Estas cerámicas presentan como elemento común, un reborde perimetral que permitiría el depósito de agua, que evitaría el acceso de insectos a la superficie. El ejemplar localizado despliega una serie de digitaciones sobre el mismo, característica común a otros tipos de cronología medieval.

El fragmento carece de borde, motivo por el cual la orientación se ha hecho en relación con esta posible utilización. Se ha asociado a una base plana de unos $14 \mathrm{~cm}$ de diámetro, cuyas características físicas se asemejan al fragmento con

\footnotetext{
${ }^{20}$ J. A. Gutiérrez GonzÁlez y R. Bohigas Roldán (coord. ed.), La cerámica medieval en el Norte y Noroeste... .

${ }^{21}$ A. Bonilla Rodríguez y M. CÉSAR Vila, “Excavaciones arqueológicas en área en el solar...”, fig. 8, núm. 1.

22 J. SuÁrez Otero et al., "La cerámica medieval en Galicia”, pág. 289.

${ }^{23}$ Luis Caballero Zoreda, et al. (eds.), Cerámicas tardorromanas y altomedievales en la Península Ibérica. Ruptura y continuidad, Madrid, Consejo Superior de Investigaciones Científicas, 2003 (Anejos de Archivo Español de Arqueología, 28), págs. 225-271.

24 Antonio Javier Murcia MuÑoz y Martín Gullermo Martínez, “Cerámicas tardorromanas y altomedievales procedentes del teatro romano de Cartagena", en Luis Caballero Zoreda, et al. (eds.), Cerámicas tardorromanas y altomedievales en la Península Ibérica. Ruptura y continuidad, Madrid, Consejo Superior de Investigaciones Científicas, 2003 (Anejos de Archivo Español de Arqueología, 28), pág. 19; fig. 3.
} 

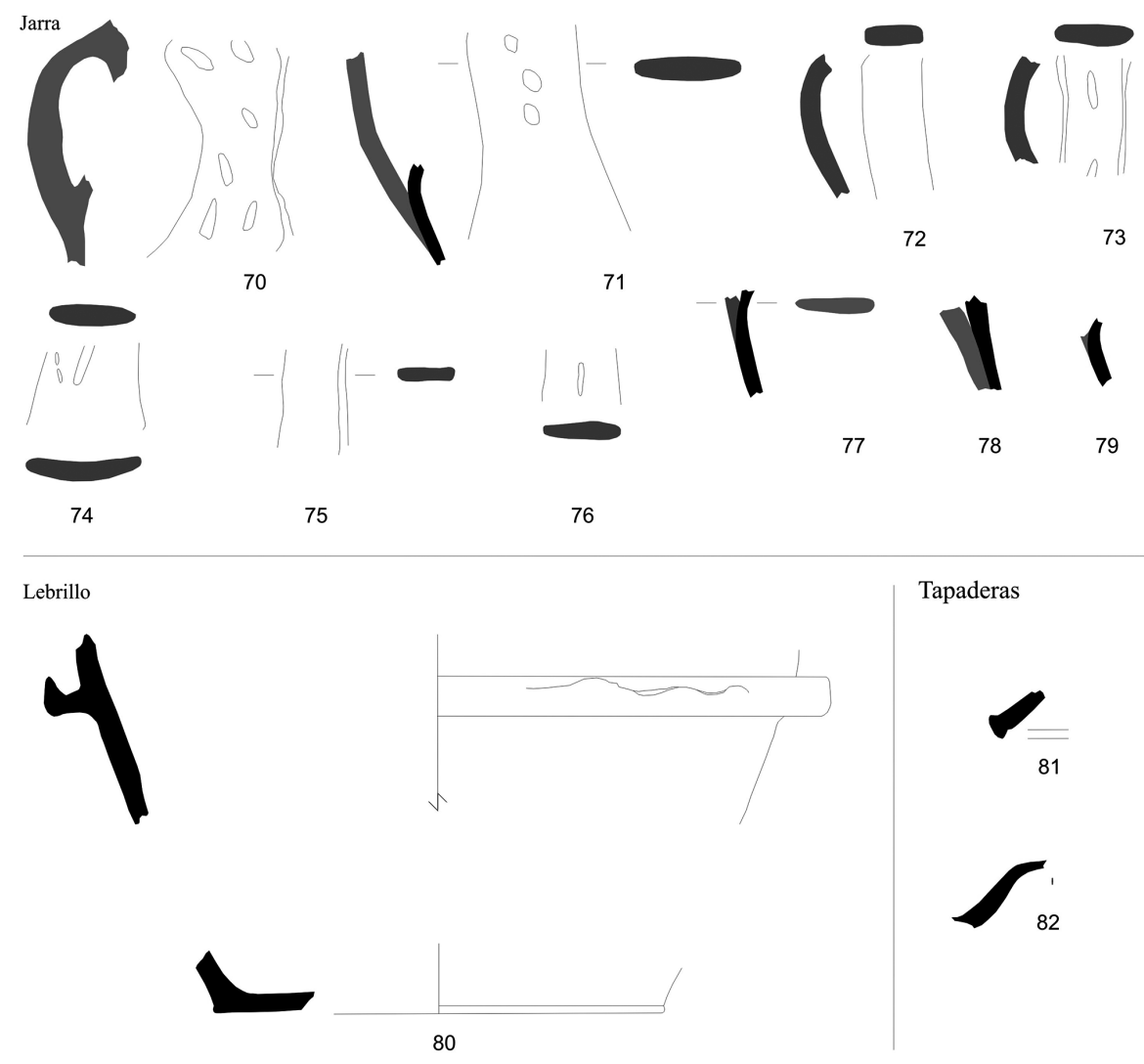

Piezas de atribución probable o inderminada

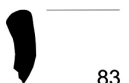

83

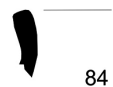

84

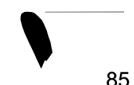

85

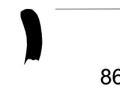

86

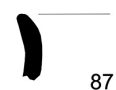

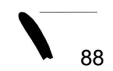

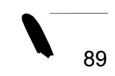

90
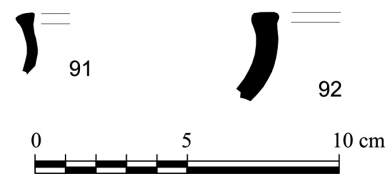

Fig. 7. Cerámica común medieval. Jarras indeterminadas (asas), lebrillo, tapaderas y piezas de atribución probable o indeterminada. 
reborde. Recipientes con esta función siguen documentándose en la edad media hasta los siglos XIV-XV, existiendo paralelos etnográficos recogidos que se fechan en los siglos XVIII-XIX ${ }^{25}$, así como en época romana, fabricados en el alfar romano de $\mathrm{Bueu}^{26}$.

Tapaderas (fig. 7: 81-82)

Han sido documentados dos ejemplares. Uno conserva borde de tipo bífido, mientras que del otro únicamente resta una parte del cuerpo, resultando ser bastante sinuoso.

Piezas de atribución probable o indeterminada (fig. 7: 83-92; fig. 8: 93-121; fig. 9: 122-145)

En este grupo se ha incluido un número elevado de piezas, que debido a la ausencia de elementos de caracterización formal o a la parcial conservación de los mismos, no han podido ser incluidos dentro de los tipos anteriormente descritos, principalmente ollas. No obstante, existen varios bordes que presentan similitudes con ciertas formas identificadas, así como otros de singular caracterización. Se presentan conjuntamente fragmentos que corresponden a arranques de cuello, cuerpos y bases que presentan alguna particularidad, así como ejemplos con elementos decorativos.

Los fondos recuperados son planos, de los que se han contabilizado 58 fragmentos, en parte con talón curvo y con talón angular o ligeramente reforzado y en algunos ejemplares con un suave resalte basal a modo de pie anular. En solo un caso se ha identificado la presencia de un fondo con umbo, elemento poco frecuente en los contextos cerámicos de este tipo. Corresponden a vasos de paredes finas (de $5 \mathrm{~mm}$ y de menos de $10 \mathrm{~mm}$, en algunos casos), al igual que las paredes de muchas ollas, que poseen bordes ligeramente o fuertemente engrosados.

En algunos casos se ha reconstruido el fondo y parece que los diámetros más frecuentes están entre los 20 y $30 \mathrm{~cm}$, medidas que podrían relacionarse con recipientes tipo olla u orza, que además suelen presentar una frecuente coincidencia entre el tamaño del fondo y el de la boca.

Los fragmentos de fondos reconstruidos dan entre 10-20 cm o incluso más diámetro y se asignan a ollas de tamaño medio o quizá de mayor capacidad. En general no es fácil conocer las capacidades de estos recipientes o al menos no parece que tengan un tamaño fijado o seriado y quizá deban estar en algún grupo de formas multiusos, tanto por la variedad de tamaños como por la diversidad de bordes.

\footnotetext{
${ }^{25}$ Rui Morais, "Potes meleiros e colmeias em cerámica: uma tradiçao milenar”, Saguntum, 38 (2006), págs. 149-161.

26 Pedro Díaz Álvarez y Manuel Vázquez VázQuez, Noticia preliminar del primer horno y alfar de ánforas gallegas, San Martiño de Bueu (Pontevedra), Vigo, P. Díaz, 1988, fig. 13.
} 

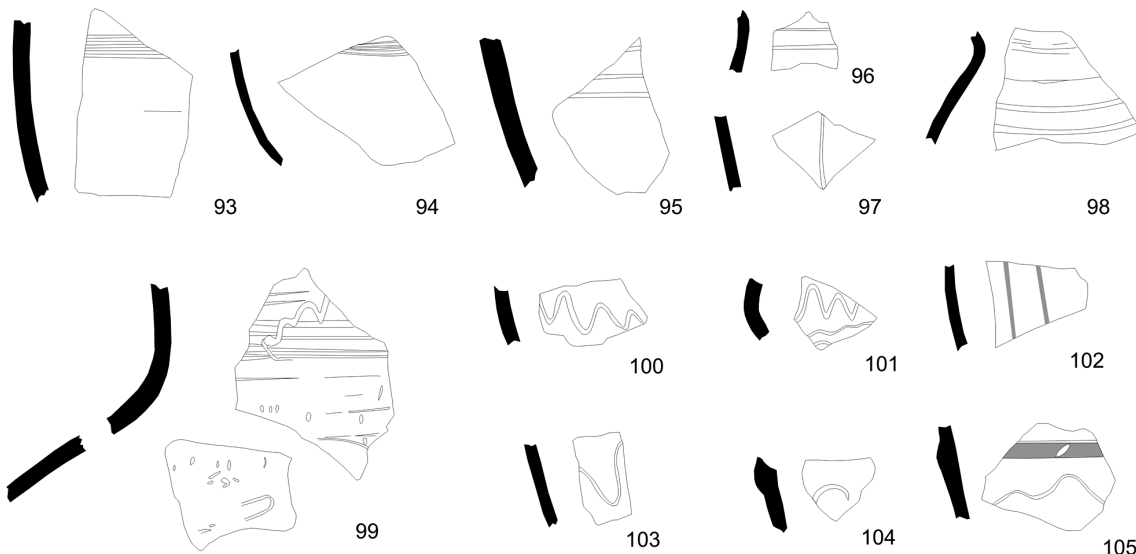

99
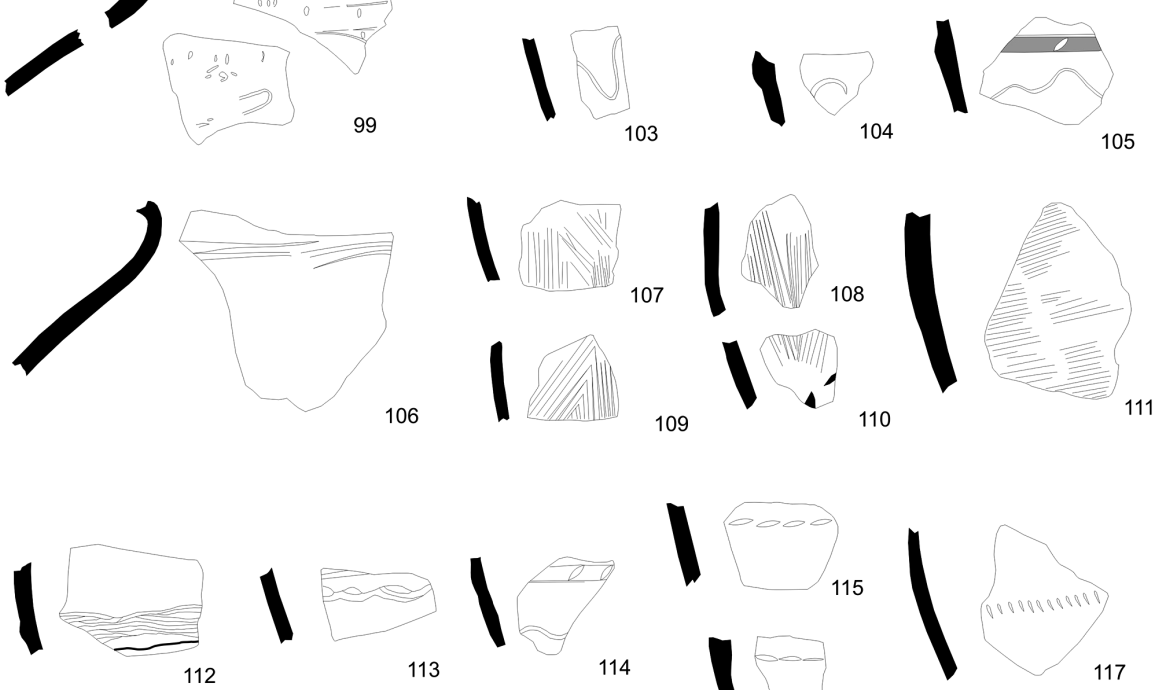

114
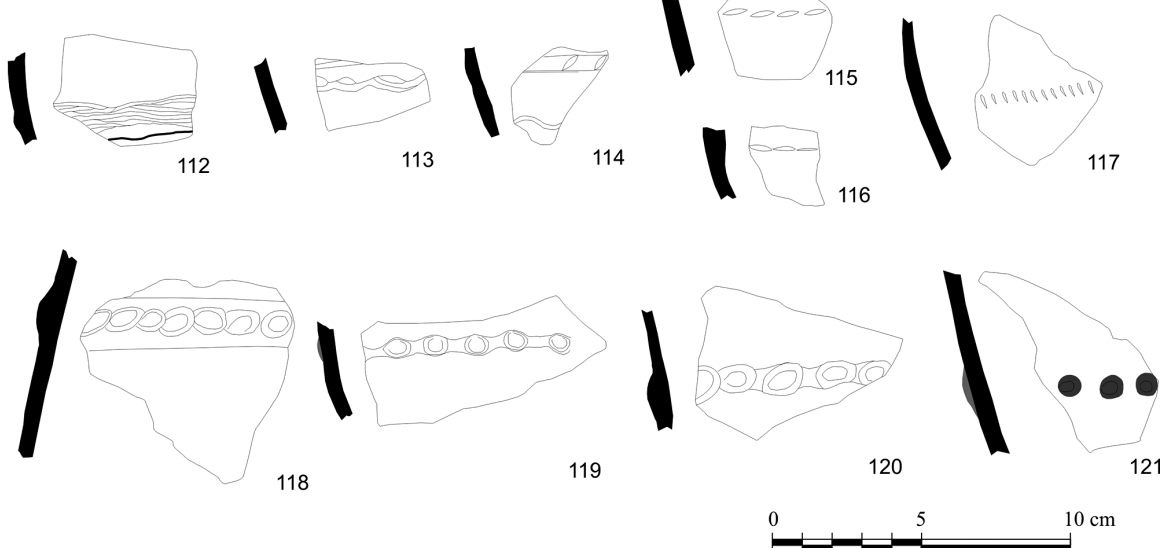

Fig. 8. Cerámica común medieval. Técnicas y motivos decorativos en piezas de atribución probable o indeterminada. 

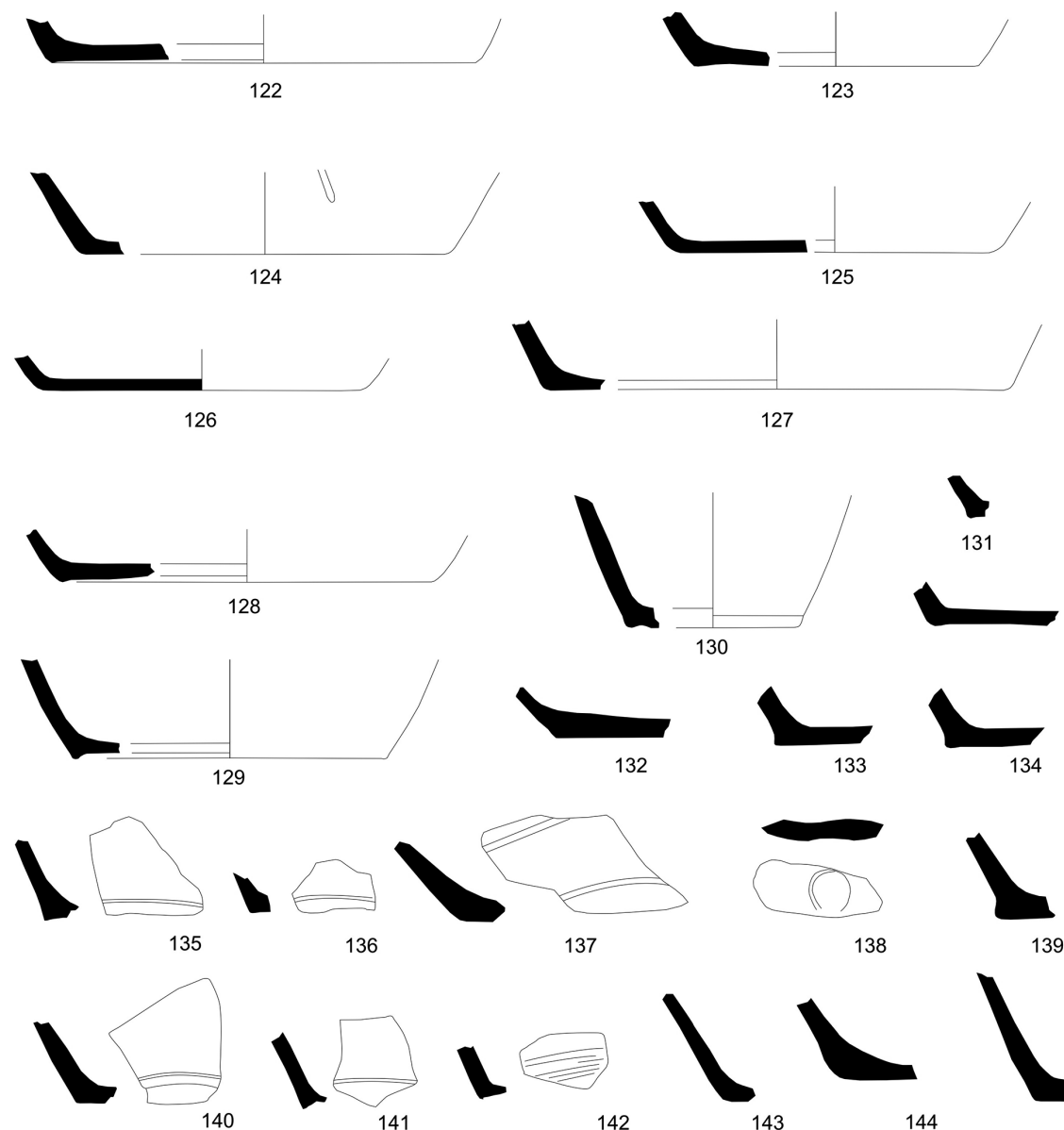

137

138

139

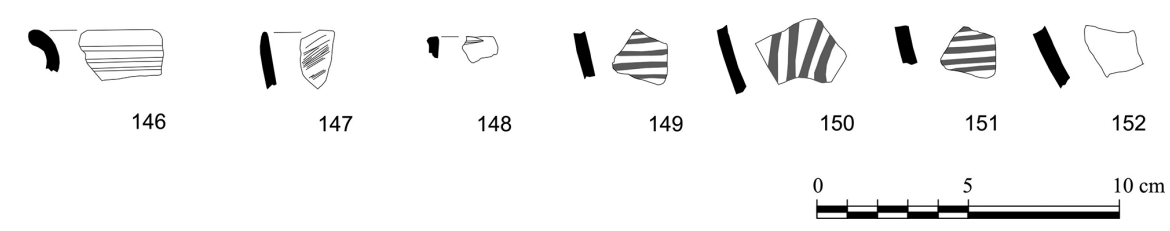

Fig. 9. Cerámica común medieval. Piezas de atribución probable o indeterminada. 


\section{TÉCNICAS Y MOTIVOS DECORATIVOS (fig. 8)}

Aunque la mayoría de la cerámica es de uso común los tratamientos superficiales y las decoraciones están presentes en todo el conjunto, mostrando cierta variedad de motivos.

Decoración de incisiones y acanalados (fig. 3: 6; Fig. 4: 22; fig. 6: 46; fig. 7: 70-71, 73-74, 76; fig. 8: 93-106; 112-114; fig. 9: 137)

Además de los característicos bruñidos y espatulados utilizados en los acabados, entre las técnicas decorativas destaca la incisión, formando motivos compuestos por acanaladuras horizontales simples o combinadas, ondulados o zig-zags generalmente horizontales o incluso oblicuos - probablemente fruto de un error-, incisiones punzantes -sobre todo en el exterior de asas en cinta-, peinados verticales, horizontales u oblicuos, en ocasiones alternándose su disposición, entre otros. En algunos casos parecen responder más a un modelo o sistema de fábrica que a verdaderas decoraciones, incluyendo algún motivo que puede interpretarse como defecto de factura.

Existen líneas horizontales incisas y acanalados muy suaves. Con frecuencia se trata de líneas estriadas agrupadas en zonas del cuerpo próximas al hombro, el arranque del cuello e incluso sobre el borde y labio, asociadas o no a tenues acanalados o formando zonas de incisiones paralelas que ocupan todo el exterior del borde. A veces marcan la zona de carena con apariencia de estriados e incluso el área del fondo. Se trata en casi todos los casos de formas de decoración que suelen estar relacionadas con el sistema de acabado de los vasos. Otras veces incluyen también líneas irregulares, que en ocasiones ni siquiera son paralelas o parecen rayados. En otros casos tanto incisiones como acanalados parecen corresponder a motivos que el tamaño de los fragmentos no permite reconocer.

Se documentan series de incisiones finas marcadas y acanalados en zonas de hombro, o en la zona de arranque de los cuellos generalmente regulares, en todos los casos producidas por el mismo procedimiento que en los casos anteriores. Solo algunas veces su posición podría formar parte de algún motivo, que por otra parte no está documentado.

También se distinguen incisiones cortas en línea recta o formando motivos en línea con incisiones cortas oblicuas a veces sobre ligeros resaltes o cordones. Algunas forman parte de motivos que resultan irreconocibles. En algunos casos parece tratarse de uñadas y ser, en este caso al menos, resultado del sistema de manufactura. En este grupo de incisiones cortas podrían incluirse algunas que parecen relacionadas con defectos de acabado. 


\section{Decoración bruñida}

Las cerámicas presentan como elemento común, además de las pastas de coloración gris, las superficies bruñidas, por lo que se puede considerar más una técnica de acabado, que una solución decorativa. En algunos fragmentos, como el borde de una jarra de boca lobulada, reflejan una superficie gris perla de calidad casi pétrea. En ciertos casos el bruñido de estas superficies ha generado una decoración de bandas más oscuras y brillantes, frente a otras zonas de superficie más mate y en otros un espatulado tan visible, que permite distinguir fácilmente los surcos del instrumento.

Digitaciones y ungulados (fig. 8: 113-117; fig. 8: 118-120)

Asimismo se ha recurrido a las digitaciones y ungulados, característicos del período medieval, formando series ceñidas generalmente a la parte superior de los cuerpos de las vasijas.

Decoración escobillada (fig. 5: 39-42; fig. 4: 48-49; fig. 8: 107-111)

En parte podría considerarse un tipo de acabado superficial, pero en algunas vasijas es tan destacado que no puede dejar de señalarse como un intento de decoración. Dentro de este grupo se incluyen una serie de ejemplares de cerámicas grises locales. La decoración suele encontrarse en los cuellos en forma de líneas verticales, pero también aparece en el cuerpo y siguiendo distintas direcciones hasta formar diseños angulares.

Concretamente, los fragmentos de diseño angular parecen tener un referente muy similar en la decoración que se encuentra en una olla del yacimiento de Zarikete, que se adscribe a la forma 8 de la clasificación de este tipo y que se describe como decorada con motivos peinados en ' $\mathrm{V}$ '27.

Decoraciones plásticas (fig. 7: 80; fig. 8: 118-121)

Se ha conservado algún fragmento con decoración plástica compuesta por serie de pequeños mamelones dispuestos horizontalmente. Estos motivos aparecen poco destacados o bien camuflados por la propia zona de rotura.

Con distintos tipos de soluciones las decoraciones con cordones más frecuentes, aparecen compuestas por resaltes que pueden formar líneas de digitaciones, aunque también pueden presentarse como un estrecho cordón festoneado y más destacable, como un reborde o pestaña en forma de solapa angular con una línea de digitaciones festoneando el borde.

\footnotetext{
27 Agustín Azcárate Garay-Olaun, et al., "Materiales y contextos cerámicos de los siglos VI al X en el País Vasco", en Luis Caballero Zoreda, et al. (ed.), Cerámicas tardorromanas y altomedievales en la Península Ibérica, Madrid, Consejo Superior de Investigaciones Científicas, 2003 (Anejos de Archivo Español de Arqueología, 28), pág. 352, fig. 22.
} 


\section{Decoración impresa}

Una técnica muy poco común, que solo aparece en forma de una huella impresa de lo que pudo ser un tejido cubriendo el cordón con botones cónicos.

\section{Engobe o baño de aguada roja}

Se trataría siempre de un baño superficial, no solo exterior, que en el caso de las aguadas suele ser muy líquido y tiene una tendencia a perder adherencia, mientras en los engobes parece haberse adherido mejor a la superficie.

\section{Cerámicas con decoración pintada}

Se han recogido dos pequeños fragmentos de pasta gris clara, bien decantada y con desgrasante fino, superficie interna del mismo color y superficie exterior con engobe y banda pintada en rojo. Un fragmento del mismo tipo totalmente pintado en rojo y bruñido, correspondiente a una vasija de pasta gris.

\section{CERÁMICA DE FABRICACIÓN EXÓGENA DE ATRIBUCIÓN PROBABLE O INDETERMINADA}

Habría que separar del grupo de las grises comunes algunos fragmentos que aunque presentan tamaño reducido, pueden adscribirse a otra producción, posiblemente de cerámicas no locales, si bien se encuadran dentro del grupo de las cerámicas comunes.

Posible olla de borde simple (fig. 9: 146)

Ha sido documentado un fragmento de borde y cuello de posible olla de borde simple, cuyas características físicas, tras el análisis macroscópico y calidad del acabado, podrían indicar una procedencia foránea, si bien esta propuesta deberá ser contrastada a través de análisis microscópicos.

Cerámica pintada (fig. 9: 149-151)

Se han distinguido escasos fragmentos de vasijas con engobe o aguadas en distintas tonalidades de rojo. En el conjunto hay tres pequeños fragmentos (entre 2 y $3 \mathrm{~cm}$ de lado) de cerámica con pastas finas y depuradas, que poseen, por lo que se aprecia en dos de ellos, superficies bruñidas de color beige y con decoración de anchas bandas pintadas en rojo, que abarcan toda o casi toda la superficie conservada.

Otro fragmento presenta pasta gris clara más compacta y su superficie posee una pintura roja bruñida algo más densa cubriéndolo en su totalidad que, si bien se interpreta como parte de una banda, podría tratarse de un engobe de calidad aplicado sobre toda la vasija. En cualquier caso, la presencia de estos fragmentos, a pesar de su pequeño tamaño, representa dos vasos distintos que poseen una decoración poco frecuente en estos conjuntos, lo que permitiría incluir las piezas entre las cerámicas que no pueden adscribirse a las grises de producción local. 


\section{Conclusiones}

A través del estudio de la cerámica de época histórica procedente de las campañas arqueológicas realizadas en Cova Eirós, se ha podido reconocer, pese a la fragmentación de los individuos, una gran uniformidad desde el punto de vista formal y productivo. Esta circunstancia ha permitido englobar, de manera preliminar, la mayor parte de los ejemplares dentro de la producción de cerámica común medieval del Noroeste peninsular, al margen de la presencia testimonial de cerámica común romana y tardorromana, así como algunas piezas que podrían pertenecer a recipientes de fabricación exógena.

Los ejemplares estudiados en Cova Eirós correspondientes a la producción de cerámica común medieval se caracterizan por presentar pastas poco depuradas y porosas, sobre las que se aprecian elementos no plásticos de cuarzo y mica, incluso en cantidades elevadas.

La presencia de "fósiles directores" de la cerámica gris medieval como la olla/ vaso de borde simple, la olla de borde horizontal cóncavo, la olla de borde de pestaña, la jarra trilobulada o el lebrillo o barreño, bien documentados en las fases plena y baja de la Edad Media, permite - a tenor de los contextos arqueológicos absolutos demostrados en Eirós- bien retrotraer el inicio de la fabricación de dichos tipos o, más probablemente, ampliar el rango temporal de las ocupaciones medievales de Eirós.

Entre las novedades que ha proporcionado el estudio hay que destacar la identificación y clasificación de grupos de cerámicas con caracteres tipológicos análogos, permitiendo la asignación de conjuntos formales no tipificados hasta el momento, o no suficientemente definidos, según se intuye a raíz del estudio historiográfico. En este sentido, la definición de tipos inéditos se ha basado en el análisis y la descripción de las características formales más singulares, principalmente proporcionadas a partir de la configuración del borde y en algunos casos también a través del desarrollo del cuello y cuerpo e incluso de la técnica y motivos decorativos asociados. Entre estos se señala la olla de borde horizontal apuntado, la olla de borde rectangular, la olla de borde biselado, la olla de borde engrosado, la olla de borde vuelto, la olla de borde corto, la olla de borde plano, la vasija de borde bífido o la jarra de borde biselado.

Asimismo se ha detectado la presencia de cuatro ejemplares que podrían vincularse con las cerámicas grises finas tardías incluidas dentro de la cerámica común romana de imitación.

Por otra parte, se pudo identificar un plato engobado de borde biselado, conocido como Tipo EP1 de la clasificación de Alcorta $^{28}$ para la cerámica común

${ }_{28}$ E. Alcorta Irastorza, , Lvcvs Avgvsti, Vol. II: Cerámica común romana...págs. 344-346. 
romana, si bien con engobe cubriente sobre ambas superficies y pasta de peor calidad en comparación con los ejemplares conocidos de Lugo.

Se ha detectado la presencia testimonial de otras piezas de pastas rojas o anaranjadas (cocción oxidante), con una decantación óptima y desgrasantes finos bien calibrados. Algunas muestran aguada de tonalidad rosada o tostada, bandas paralelas realizadas mediante bruñido e incluso algunas con pigmento. El estado de fragmentación, ha impedido la caracterización formal, si bien, a modo de hipótesis y en función de sus características formales y decorativas, podrían estar relacionadas con tipos de las fases romana Altoimperial o Tardorromana.

Desde el punto de vista cronológico, las dataciones radiocarbónicas de los contextos estratigráficos asociados han proporcionado fechas entre los siglos $\mathrm{X}$ y XI d.C, cronologías coherentes para los tipos de cerámica común identificados. Por otra parte, la presencia de ejemplares que podrían vincularse a etapas históricas precedentes (tardorromana o altomedieval), indicarían una reocupación de la cueva en época histórica durante momentos anteriores al señalado por el grueso de las cerámicas y las dataciones absolutas, que en este caso marcarían la fase de amortización del hábitat. Por otra parte, la presencia de ciertos elementos que se encuadrarían en las épocas plena o baja de la Edad Media podrían indicar ocupaciones posteriores de la cavidad.

La presencia de ejemplares que podrían vincularse con cerámicas grises finas tardías de imitación de modelos de la TSAD, no debe considerarse un hecho aislado. En este sentido cabe señalar que la presencia incluso de TSHT no es ajena a otros contextos cavernarios peninsulares, si bien son formas diferentes a las identificadas en Cova Eirós. En Galicia, se han identificado restos de Terra sigillata (Forma 37) en la Cova de Xato (Folgoso do Courel, Lugo) y Pala da Zorra (Rubiá, Ourense), vinculadas a estancias cortas y esporádicas que, en caso de Pala da Zorra, se relacionan con centros eremíticos ${ }^{29}$. En otros yacimientos cantábricos se documentan numerosas ocupaciones de cavidades en torno a los siglos IV-VI AD que presentan una funcionalidad heterogénea. Estas ocupaciones o bien están ligadas a contextos eremíticos o rituales (vg. Arlanpe $)^{30} \mathrm{o}$ bien a contextos domésticos (de mayor o menor entidad) de carácter ganadero ${ }^{31}$. Si bien los

\footnotetext{
${ }^{29}$ Ramón FÁbregas Valcarce et al., "Aportacións ó estudo da Prehistoria da cunca media do Miño. Os asentamentos en cova e ó aire libre”, Gallaecia, 27 (2008), págs. 63-88; Carlos Fernández RodríGuez, et al., "Prospección arqueológica de cavidades en la Sierra de la Encina de la Lastra (Rubiá, Ourense): Primeros resultados", en Actas del XXII Congreso Nacional de Arqueología, vol. 2, Vigo, Xunta de Galicia, 1993, págs. 43-48.

${ }^{30}$ Enrique Gutiérrez Cuenca et al., "El uso de la cueva de Arlanpe (Bizkaia) en época tardorromana", Archivo Español de Arqueología, 85 (2012), págs. 229-251.

31 José Antonio Quirós CAstillo, "La génesis del paisaje medieval en Álava: la formación de la red aldeana”, Arqueología y Territorio Medieval, vol. 13, núm. 1 (2006), págs. 49-94; Alfonso Fanjul Peraza, "Las últimas cuevas. Observaciones en torno a la ocupación histórica de las cuevas astur-leonesas", Arqueología y Territorio Medieval, 18 (2011), págs. 91-116.
} 
datos son escasos, la zona oriental de Galicia y próxima a Cova Eirós muestra un importante poblamiento desde época castreña y, especialmente, romana vinculada a la explotación de recursos auríferos o férricos de la zona de $\mathrm{O}$ Courel y áreas adyacentes (O Incio, Valle del Sil, etc) $)^{32}$.

Por otra parte, la presencia de cerámicas engobadas, si bien presentan cronología amplia, podrían estar indicando el uso de la cueva en momentos del Alto Imperio. Debe señalarse que no se advierte ruptura en la llegada de terra sigillata de fabricación hispana altoimperial al paso a los siglos bajoimperiales. Esta realidad fue explicitada en su día por Naveiro ${ }^{33}$ y corroborada a partir de nuestros estudios específicos posteriores ${ }^{34}$.

Sin embargo, el material cerámico, las estructuras de almacenaje de la entrada y las dataciones absolutas remiten a una intensa actividad durante la transición de los siglos X-XI A.D. ${ }^{35}$. La documentación histórica se refiere a la existencia del lugar de Cancelo ya en el año 1096 A.D., siendo su iglesia anterior al 1176 A.D. ${ }^{36}$. En ese sentido, se deben entender las estructuras de almacenaje de la entrada de Cova Eirós como un espacio complementario dentro de la economía agropastoril de las comunidades del núcleo inmediato de Cancelo.

A una mayor escala, las evidencias arqueológicas de Cova Eirós son el reflejo de los cambios en la estructuración del territorio que se producen entre los siglos VIII-XI en el Noroeste peninsular y que son la raíz del poblamiento rural gallego ${ }^{37}$.

\footnotetext{
32 José María Luzón Nogué et al., El Caurel, Madrid, 1980 (Excavaciones arqueológicas en España, 110). 33 Juan NAVEIRo LóPEZ, El comercio antiguo en el N.W. peninsular: lectura histórica del registro arqueológico, A Coruña, Museo Arqueolóxico e Histórico, 1991 (Monografías Urxentes do Museu, 5), pág. 244.

${ }^{34}$ Mario CÉSAR VILA, A terra sigillata do xacemento romano de Bueu e o seu contexto no marco pontevedrés, memoria de licenciatura, Santiago de Compostela, Universidade de Santiago de Compostela, 2009; M. César Vila y M. C. López Pérez, “Aportaciones al conocimiento del comercio de sigillata...”, págs. 243; María Catalina López PÉrez y Mario CÉSAR VILA, "La importación de Terra Sigillata durante la etapa tardorromana en la fachada atlántica del Noroeste peninsular", Metodología de Análisis Aplicada a los Estudios de Cerámica Tardoantigua y Medieval de la Península Ibérica, Jornada internacional sobre metodología de análisis aplicada a los estudios de cerámica tardoantigua y medieval de la Península Ibérica, León, Universidad de León, 2010, págs. 41-52; María Catalina LóPez Pérez et al., "Las producciones de TSHT en el área galaica: Difusión, tipología y decoración”, Ex Officina Hispana. Cuadernos de la SECAH, 1 (2013), págs. 126-127.

35 A. Teira Brión et al., "Forest resource management...”; R. FÁBregas Valcarce et al., “Ocupacións prehistóricas e históricas...", págs. 19-46.

${ }^{36}$ Ramón Yzquierdo Perrín, "El mecenazgo de los Quiroga en San Cristóbal de Cancelo", Sémata, 2 (1989), págs. 269-289.

37 Jorge López Quiroga y Mónica Rodríguez Lovelle, "Un modelo de evolución del poblamiento rural en la Galicia interior (S. V-X): El territorio en torno a la Depresión de Sarria y al monasterio de Samos", Boletín do Museo Provincial de Lugo, 9 (1999-2000), págs. 173-185; José Carlos SÁnchez PArdo, "Poblamiento rural tardorromano y altomedieval en Galicia (SS. V-X). Una revisión arqueológica", Archaeologia Medievale, 37 (2010), págs. 285-306; Alfonso Vigil-Escalera Guirado y Juan Antonio, Quirós Castillo, "Arqueología de los paisajes rurales altomedievales en el Noroeste Peninsular", en Luis Caballero Zoreda (ed.), Visigodos y Omeyas. El Territorio, Mérida, Consejo Superior de Investigaciones Científicas, 2012 (Anejos de Archivo Español de Arqueología, 61), págs. 79-95.
} 

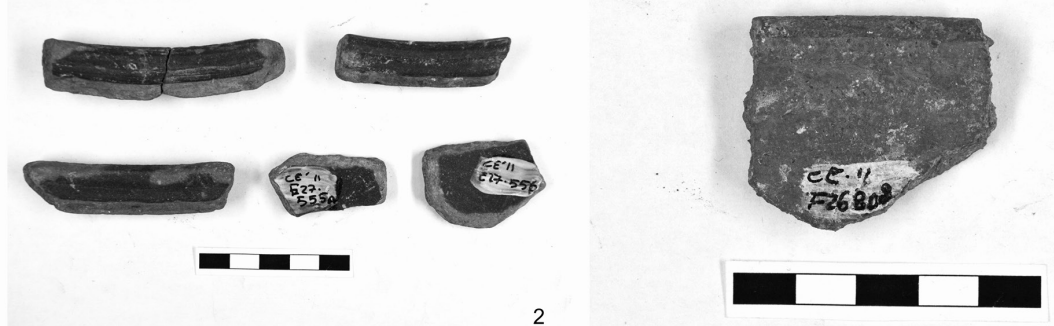

Cerámica medieval: Olla de borde horizontal apuntado

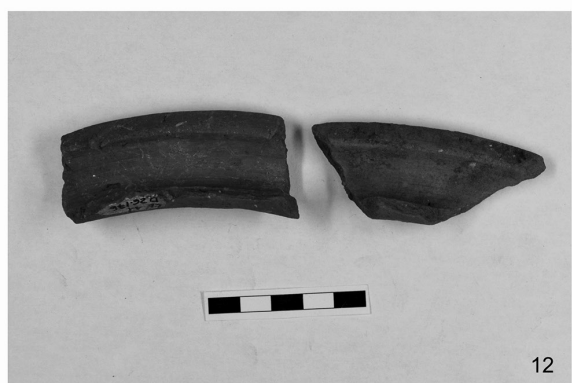

Olla de borde biselado

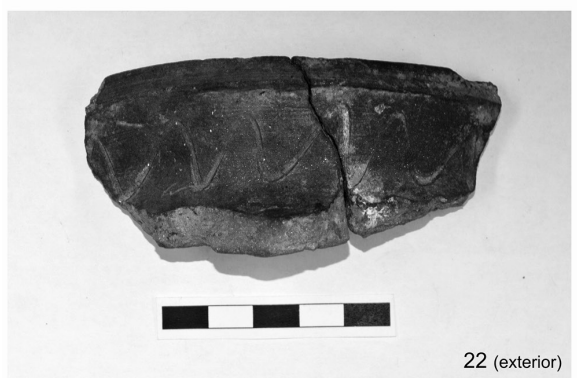

Olla de borde rectangular

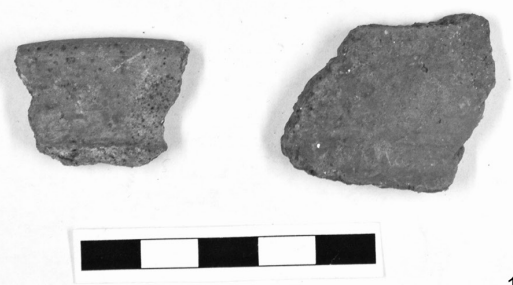

17

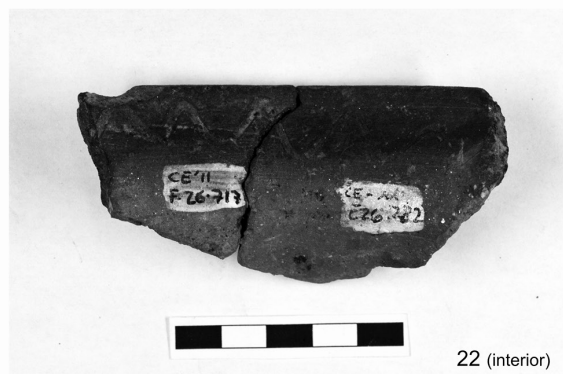

Lámina 1. Cerámica común romana: cerámicas grises finas tardías y plato engobado de borde biselado EP1. Cerámica común medieval: olla de borde horizontal apuntado, olla de borde rectangular y olla de borde biselado. 
Olla de borde biselado

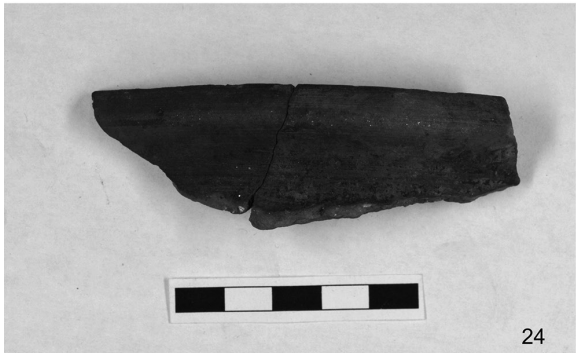

Olla de borde corto

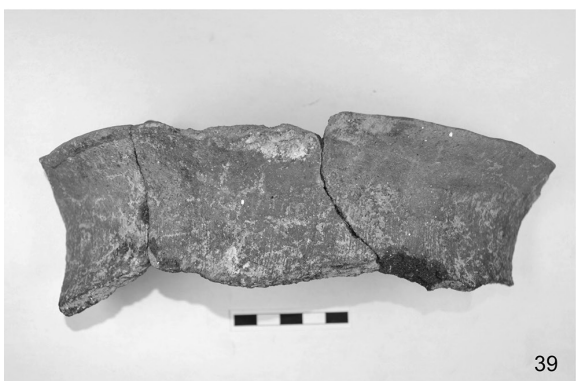

Olla de borde vuelto

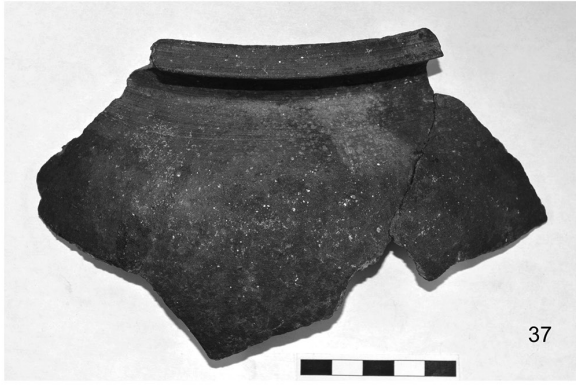

Lebrillo

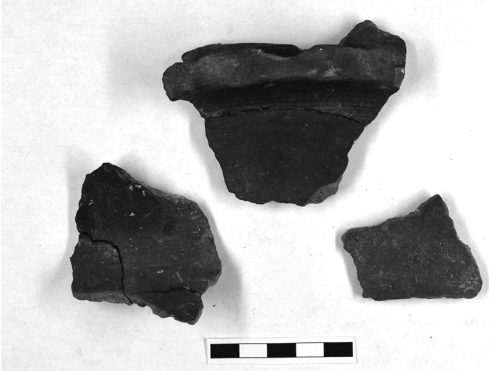

80

Lámina 2. Cerámica común medieval: olla de borde biselado, olla de borde vuelto, olla de borde corto y lebrillo.

La singularidad del yacimiento de procedencia, la preservación de conjuntos estratigráficos cerrados, la identificación de tipos inéditos no suficientemente sistematizados en el Noroeste peninsular, sumado a las cronologías propuestas para los materiales -con escasos paralelos conocidos en el NW peninsular-, justifican suficientemente la necesidad de ampliación y desarrollo de la investigación de los materiales históricos procedentes del yacimiento de Cova Eirós, así como de sus contextos y entorno.

\section{BIBLIOGRAFÍA}

Alcorta Irastorza, Enrique, Lvcvs Avgvsti, Vol. II: Cerámica común romana de cocina y mesa hallada en las excavaciones de la ciudad, A Coruña, Fundación Pedro Barrié de la Maza, 2001.

Azcárate Garay-Olaun, Agustín; Núñez Marcén, Julio y Solaun Bustinza, José Luis, "Materiales y contextos cerámicos de los siglos VI al X en el País Vasco", en Luis Caballero Zoreda, et al. (ed.), Cerámicas tardorromanas y altomedievales en la Península Ibérica, Madrid, 
Consejo Superior de Investigaciones Científicas, 2003 (Anejos de Archivo Español de Arqueología, 28), págs. 321-370.

Bartolomé Abraira, Roberto, "Cerámica gris fina tardía. Los fondos resaltados de copas y cuencos carenados de Lucus Augusti”, Férvedes, 8, Vilalba (Lugo), 2015, págs. 371-380.

Bonilla Rodríguez, Andrés y César Vila, Mario, "Excavaciones arqueológicas en área en el solar de la antigua capilla y lazareto medieval de S. Lázaro (Santiago de Compostela, A Coruña)", Gallaecia, 24 (2005), págs. 219-242.

Cailleux, André, Notice sur le code des couleurs des sols, Paris, Boubée, 1963.

César Vila, Mario, A terra sigillata do xacemento romano de Bueu e o seu contexto no marco pontevedrés, Memoria de Licenciatura, Santiago de Compostela, Universidade de Compostela (2009).

César Vila, Mario y Bonilla Rodríguez, Andrés, "Estudio de los materiales cerámicos del "Castelo da Lúa" (Rianxo, A Coruña)", Gallaecia, 22 (2003), págs. 297-367.

César Vila, Mario y Bonilla Rodríguez, Andrés, "Síntesis de los materiales cerámicos procedentes del yacimiento de As Encrobas (Cerceda A Coruña)", en La cerámica en Galicia: de los castros a Sargadelos. Actas del XIV Congreso Anual, [Alicante], Asociación de Ceramología, 2011, págs. 141-152.

César Vila, Mario; Bonilla Rodríguez, Andrés y López Pérez, María Catalina, "Aportaciones al conocimiento de la cerámica producida en la última fase de la Edad media en Galicia", Metodología de Análisis Aplicada a los Estudios de Cerámica Tardoantigua y Medieval de la Península Ibérica, Jornada internacional sobre metodología de análisis aplicada a los estudios de cerámica tardoantigua y medieval de la Península Ibérica, León, Universidade de León, 2010, págs. 145-160.

César Vila, Mario y López Pérez, María Catalina, “Aportaciones al conocimiento del comercio de sigillata en la fachada Atlántica del Noroeste Peninsular", Les productions céramiques en Hispanie Tarraconaise (IIe s. av. J.-C. -VIe s. apr. J.-C.) Actualité des recherches céramiques, Actes du Congrès de L'Escala-Empúries, Marseille, 2008, págs. 241-254.

Díaz Álvarez, Pedro y Vázquez Vázquez, Manuel, Noticia preliminar del primer horno y alfar de ánforas gallegas, San Martiño de Bueu (Pontevedra), Vigo, P. Díaz, 1988.

Fábregas Valcarce, Ramón; Alonso Fernández, Susana; Lazuén Fernández, Talía; de Lombera Hermida, Arturo; Pérez Alberti, Augusto; Rodríguez Álvarez, Xosé Pedro; Rodríguez Rellán, Carlos; Terradillos Bernal, Marcos; Serna González, María Remedios y Vaquero Rodríguez, Manuel, "Aportacións ó estudo da Prehistoria da cunca media do Miño. Os asentamentos en cova e ó aire libre”, Gallaecia, 27 (2008), págs. 63-88.

Fábregas Valcarce, Ramón; de Lombera Hermida, Arturo; Serna González, María Remedios; Vaquero Rodríguez, Manuel; Pérez Rama, Marta; Grandal D'Anglade, Aurora; Rodríguez Álvarez, Xosé Pedro; Alonso Fernández, Susana y Ameijenda Iglesias, Alicia, “Ocupacións prehistóricas e históricas nas cavidades das Serras Orientais galegas. As covas de Eirós (Triacastela) e Valdavara (Becerreá)", Gallaecia, 31 (2012), págs. 19-46.

Fanjul Peraza, Alfonso, "Las últimas cuevas. Observaciones en torno a la ocupación histórica de las cuevas astur-leonesas”, Arqueología y Territorio Medieval, 18 (2011) págs. 91-116.

Fariña Busto, Francisco, "Contribución ao estudo da cerámica medieval en Galicia”, Cuadernos de Estudios Gallegos, 29, fasc. 87-89 (1974-75), págs. 51-64. 
MARIO CÉSAR VILA, ARTURO DE LOMBERA HERMIDA, RAMÓN FÁBREGAS VALCARCE, XOSÉ-PEDRO RODRÍGUEZ-ÁLVAREZ

Fernández Fernández, Adolfo; Bartolomé Abraira, Roberto, "Cerámicas tardoantiguas en el Noroeste de la Península (Galicia y norte de Portugal: entre la importación y el artesanato local/regional (ss. V-VII)", en La cerámica de la Alta Edad Media en el cuadrante Noroeste de la Península Ibérica (siglos V-X), Sistemas de producción, mecanismo de distribución y patrones de consumo, Documentos de Arqueología Medieval, 9, Bilbao, Universidad del país Vasco, 2016, págs. 69-111.

Fernández Rodríguez, Carlos; Villar Quinteiro, Rosa; Llana Rodríguez, José César y Doval Galán, José Francisco, "Prospección arqueológica de cavidades en la Sierra de la Encina de la Lastra (Rubiá, Ourense): Primeros resultados", en Actas del XXII Congreso Nacional de Arqueología, vol. 2, Vigo, Xunta de Galicia, 1993, págs. 43-48.

Gutiérrez Cuenca, Enrique; Hierro Gárate, José Ángel; Ríos-Garaizar, Joseba; Gárate Maidagan, Diego; Gómez-Olivencia, Asier y Arceredillo Alonso, Diego, "El uso de la cueva de Arlanpe (Bizkaia) en época tardorromana", Archivo Español de Arqueología, 85 (2012), págs. 229-251.

Gutiérrez González, José Avelino y Bohigas Roldán, Ramón (coord. ed.), La cerámica medieval en el Norte y Noroeste de la Península Ibérica. Aproximación a su estudio, León, Universidad de León, 1989.

López Pérez, María Catalina; Carreño Gascón, Covadonda y César Vila, Mario, "Las producciones de TSHT en el área galaica: Difusión, tipología y decoración", Ex Officina Hispana. Cuadernos de la SECAH, 1 (2013) págs. 125-138.

López Pérez, María Catalina y César Vila, Mario, "La importación de Terra Sigillata durante la etapa tardorromana en la fachada atlántica del Noroeste peninsular", Metodología de Análisis Aplicada a los Estudios de Cerámica Tardoantigua y Medieval de la Península Ibérica, Jornada internacional sobre metodología de análisis aplicada a los estudios de cerámica tardoantigua y medieval de la Península Ibérica, León, Universidad de León, 2010, págs. 41-52.

López Quiroga, Jorge y Rodríguez Lovelle, Mónica, “Un modelo de evolución del poblamiento rural en la Galicia interior (S. V-X): El territorio en torno a la Depresión de Sarria y al monasterio de Samos", Boletín do Museo Provincial de Lugo, 9 (1999-2000), págs. 173-185.

Luzón Nogué, José María; Sánchez-Palencia Ramos, Francisco Javier; Acuña Castroviejo, Fernando; Alonso del Real, Carlos; Arias Vilas, Felipe; Caamaño Gesto, José Manuel; Rodríguez Casal, Antón; Sierra Rodríguez, José Carlos y Vázquez Varela, José Manuel, El Caurel, Madrid, 1980 (Excavaciones arqueológicas en España, 110).

Morais, Rui, "Potes meleiros e colmeias em cerámica: uma tradiçao milenar", Saguntum, 38 (2006), págs. 149-161.

Murcia Muñoz, Antonio Javier y Guillermo Martínez, Martín, "Cerámicas tardorromanas y altomedievales procedentes del teatro romano de Cartagena", en Luis Caballero Zoreda, et al. (eds.), Cerámicas tardorromanas y altomedievales en la Península Ibérica. Ruptura y continuidad, Madrid, Consejo Superior de Investigaciones Científicas, 2003 (Anejos de Archivo Español de Arqueología, 28), págs. 169-223.

Naveiro López, Juan, Los materiales arqueológicos de la Plaza de María Pita (A Coruña), Memoria inédita, 1986. 
Naveiro López, Juan, El comercio antiguo en el N.W. peninsular: lectura histórica del registro arqueológico, A Coruña, Museo Arqueolóxico e Histórico, 1991 (Monografías Urxentes do Museu, 5).

Paz Peralta, Juan Ángel, "Las producciones de terra sigillata hispánica intermedia y tardía”, en Darío Bernal Casasola y Albert Ribera i Lacomba (coords.), Cerámicas hispanorromanas. Un estado de la cuestión, Cádiz, Universidad de Cádiz, 2008, págs. 497-539.

Quirós Castillo, José Antonio, "La génesis del paisaje medieval en Álava: la formación de la red aldeana", Arqueología y Territorio Medieval, vol. 13, núm. 1 (2006), págs. 49-94.

Sánchez Pardo, José Carlos, "Poblamiento rural tardorromano y altomedieval en Galicia (SS. V-X). Una revisión arqueológica", Archaeologia Medievale, 37 (2010), págs. 285-306.

Suárez Otero, José; Gimeno García-Lomas, Rosa y Fariña Busto, Francisco, "La cerámica medieval en Galicia”, en José Avelino Gutiérrez González y Ramón Bohigas Roldán (coord. ed.), La cerámica medieval en el Norte y Noroeste de la Península Ibérica. Aproximación a su estudio, León, Universidad de León, 1989, págs. 285-301.

Teira Brión, Andrés; Martín Seijo, María; de Lombera Hermida, Arturo; Fábregas Valcarce, Ramón y Rodríguez Álvarez, Xosé Pedro, "Forest resource management during Roman and Medieval cave occupations in the Northwest of the Iberian Peninsula: Cova do Xato and Cova Eirós (Lugo, Galicia, Spain)”, Saguntum. núm. extra 13 (2012), págs. 159-166.

Vigil-Escalera Guirado, Alfonso y Quirós Castillo, Juan Antonio, “Arqueología de los paisajes rurales altomedievales en el Noroeste Peninsular", en Luis Caballero Zoreda (ed.), Visigodos y Omeyas. El Territorio, Mérida, Consejo Superior de Investigaciones Científicas, 2012 (Anejos de Archivo Español de Arqueología, 61), págs. 79-95.

Yzquierdo Perrín, Ramón, "El mecenazgo de los Quiroga en San Cristóbal de Cancelo", Sémata, 2 (1989), págs. 269-289. 